\title{
Use of Explicit FEM models for the structural and parametrical analysis of rockfall protection barriers
}

\author{
Castanon-Jano, L., Blanco-Fernandez, E., Castro-Fresno, D., Ferreño D.
}

\begin{abstract}
This paper illustrates the experimental test procedure and results of two flexible barriers of low and medium energy, the so-called IBT-150 and IBT-500. For this purpose, ETAG 027 European Guideline is used. All the requirements for the tests performance are followed and the two energylevel tests performance requirements have been fulfilled in both rockfall barriers. Numerical modeling helps to understand and predict the behavior of these barriers with different configurations drastically reducing the costs of performing real tests. The results of the real test on IBT-150 and IBT-500 have been taken as references to validate two numerical models using Abaqus Explicit software. Afterwards, a presentation of some alternatives of the barrier IBT-150 are stated, which allow a more economical design removing some components that do not affect the energy level of $150 \mathrm{~kJ}$ set by the manufacturer. Also, a parametrical analysis of the IBT-500 numerical model has been performed varying the geometrical characteristics, such as the net grid dimension, the diameter of the perimeter cable, the length of the functional modules and its height. The aim of this analysis is the enhancement of maximum energy capacity of the barrier related with the amount of material used to build it. Following the ETAG recommendation, the maximum energy level (MEL) test is achieved if the barrier is able to retain the block. Thus, the MEL level for each numerical model was determined by increasing the initial speed of the block until it trespasses the barrier.
\end{abstract}

\section{Keywords}

Rockfall barrier, interception nets, numerical modelling, parametric analysis, geometric variables

\section{Introduction}

Flexible barriers have the function of retaining falling rocks from a slope. They are made of an interception net, posts, perimeter, lateral and upstream cables, and energy dissipating devices, also known as brakes. In the development of these structures, almost all the components have been studied in order to adapt the barrier design to the energy dissipation aim. This is the case of the brakes, which can have a wide range of shapes with different absorption capacities, and can be placed in different number and parts, including side, upstream or perimeter cables [1]. The perimeter cables also have a relevant role. A higher number of perimeter cables in each side allow the placement of more brakes. Moreover, an alternative sewing of the interception structure means a lower damage risk of them around the post ends. Several interception nets have also been developed, using square pattern cable nets, wire ring nets or omega cable wire nets.

In order to numerically reproduce the behavior of barriers, experimental tests of the structure of interest must be done first [2], not only of the full barrier but also each of the components independently [3]. The increasing use of codes based on the Finite Element Method (FEM) in these structures resulted in a vast amount of numerical models able to reproduce its behaviour due 
to an impact. The most simplified models on the literature are 2D [4] representing only the profile of the barrier: one upstream cable, one post and the net represented by two lines linked together in a central point where the block impact takes place. Regarding 3D simplest models [5], they are obtained by reducing the contact interactions between elements of the barrier to the minimum, being the only one located between the block and the barrier, and by generating an equivalent model of the ring net. On the other hand, more complex models [6,7] are aimed to be more realistic: actual connections between perimeter and interception structure and real geometry of the interception structure, which result in a more accurate but also more time consuming model.

The success in the development of a numerical model of these barriers helped in many cases to investigate the influence of several parameters in order to reach a better understanding of the behavior of such complex structures. The size of the impacting mass has been analyzed by Cazzani et al. and Mentani et al. [8,9]. Giving a step forward, Koo et al. [10] compared an impact of a spherical block with a slab-shape block. In addition, Volkwein et al. [11] studied the effect of two loads with very different impact areas, being the first a tree trunk with a very sharp head, and the second one a debris flow with a distributed loading area along all the net.

Another parameter that has been studied is the angle between the trajectory of the block and the barrier. Moon et al. [12] used angles of $65^{\circ}, 60^{\circ}$ and $45^{\circ}$, whilst Mentani et al. [13] did a deeper study selecting positive and negative angles of $-60^{\circ},-30^{\circ}, 0^{\circ}, 30^{\circ}$ and $60^{\circ}$ in order to consider both the descendent trajectory relative to the slope and the ascendant one after a rebound in the slope. Numerous authors considered the influence of the location of the impact. This parameter was evaluated both in a simple net panel [8] and in the context of the full barrier model $[13,14,15]$. The influence of the speed and hence the bullet effect was a matter of interest for Volkwein et al. [11].

The aforementioned parametrical analysis are related with the block shape, impact location and trajectory. Concerning geometrical parameters of the barrier, Moon et al. [12] takes into account the post spacing using distances of 7, 8, 9 and $10 \mathrm{~m}$. However, his study aims to observe the variations in loads of cables and foundations after applying the same energy impact to the 4 different models, and it is not focused on finding its maximal energy capacity.

A different type of geometrical analysis found in the literature was done by Escallón et al. [16]. It is related to the optimization of several geometrical parameters of a wire net that minimizes the error between an experimental tensile test and its equivalent numerical model. The aim of this study was to find the highest fidelity of the full barrier numerical model by strictly adjusting each component, but, as it happens with the previous geometric study, maximal energy capacity is not explored.

With the purpose of covering this gap, this paper will develop an investigation of barriers IBT150 and IBT-500 and its parametrical analysis in terms of four geometrical variables: length and height of the functional module, grid size and cable diameter of the net.

To have a reliable model for the geometrical analysis, a numerical model for each barrier is firstly performed and then validated using experimental tests results. Abaqus Explicit package will be used for this aim.

Additionally, the low energy barrier IBT-150 is modified in terms of the number and location of energy dissipating devices to determine the most economical design whilst keeping its energy retention capacity.

\section{Experimental tests}


IBT150 barrier has three functional modules of 10 metres long and 3 metres width. The interception structure is a square pattern cable net with a square side size of $200 \mathrm{~mm}$. The perimeter cables have $16 \mathrm{~mm}$ diameter and the posts have a pipe profile, with an external diameter of $125 \mathrm{~mm}$ and a thickness of $4 \mathrm{~mm}$. The barrier has four upstream cables of $6 \mathrm{~m}$ long, one in each post, and four side cables, two in each side, of 4 and $5 \mathrm{~m}$ long. Each of the upstream and side cables has an energy dissipation device.

IBT500 barrier has three functional modules of 10 metres long and 4 metres width. The interception structure is similar than that of the IBT150. The perimeter cables have $22 \mathrm{~mm}$ diameter and the posts have a HEB profile. In this configuration, the barrier has eight upstream cables of $8.8 \mathrm{~m}$ long and $16 \mathrm{~mm}$ diameter, two in each post, and four side cables, two in each side, of 6.8 and $7.8 \mathrm{~m}$ long and also $16 \mathrm{~mm}$ diameter. Each of the upstream and side cables has an energy dissipation device. A small pretension $(22 \mathrm{kN})$ was induced in side cables in both barriers.

The geometric details of both barriers, as well as the position of the sensors placed in the experimental tests are showed in Figure 1.

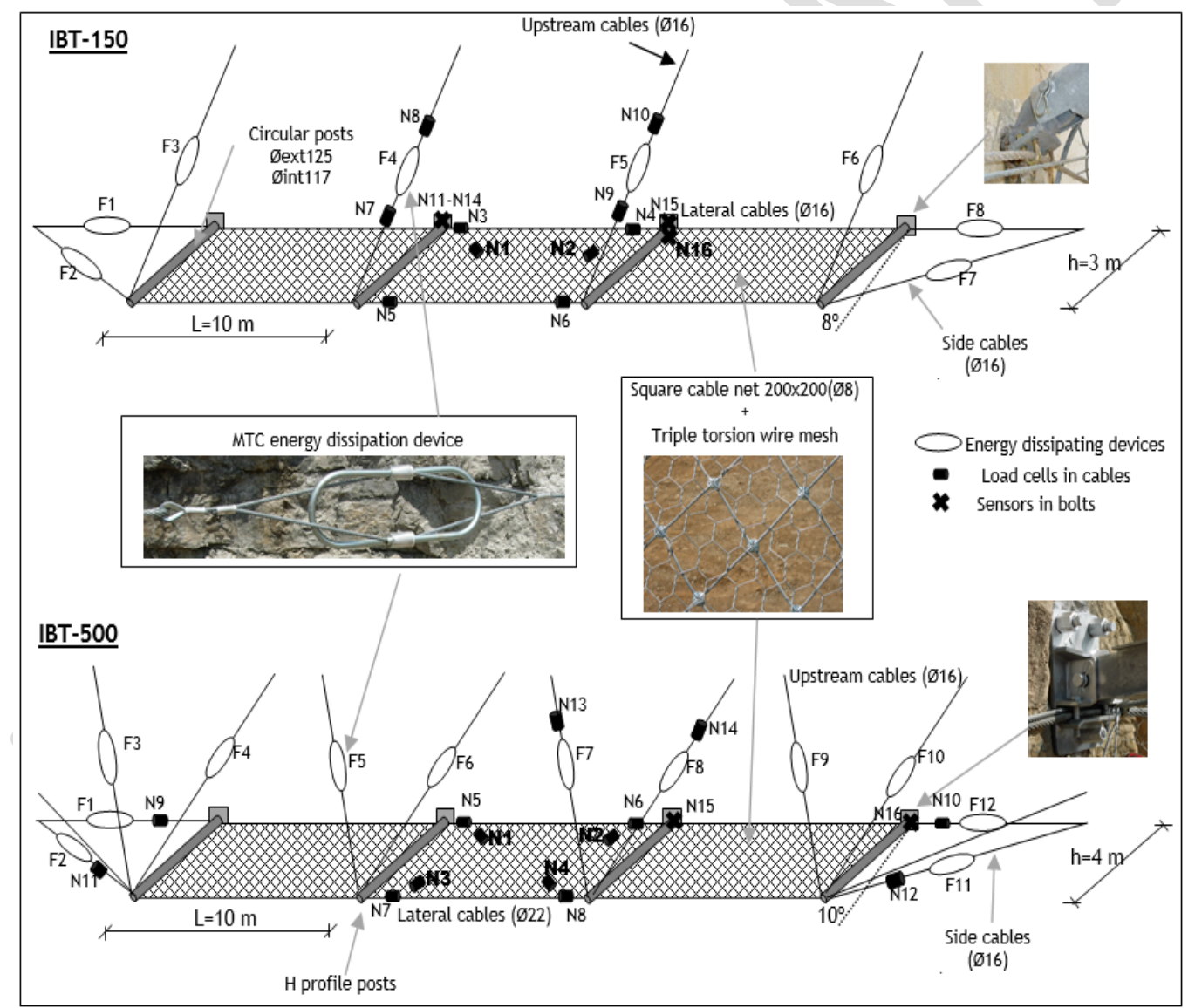

Figure 1. Specifications and sensor location of flexible barriers IBT-150 and IBT-500

The tests were performed following the ETAG 027 [17], a guideline for European Technical Approval that stablishes the fitness for use of a barrier (also referred as 'kit'). The test is based in dropping a concrete block in a barrier. A vertical free-fall configuration was used, which is one of the two options -vertical or inclined- contemplated by the guideline. Two different energy levels are defined in it: a service energy level (SEL) and a maximum energy level (MEL), being 
the MEL three times the SEL. For the SEL test, two successive launches are carried out without possibility of changing any component of the barrier, in order to check the barrier's capacity of resisting several impacts. After the second launch the block must be retained by the barrier. The MEL test is related with the maximum capacity of the barrier. It consists in only one launch, and it will be passed if the barrier is able to stop the block. Although the guideline allows the fixing or substitution of the barrier between the second SEL and the MEL impacts, in these two barriers' test, there were no changes in any component. This decision was taken based in two facts: there were no ruptures in any of the components, and there is also a significant saving of money and time for the company due to the installation of such a big structure. The non-substitution of components means a reduction of a retention capacity of the barrier in the third impact (the MEL one). However, a barrier passing the test in these conditions is considered to be on the conservative side.

Tests in IBT-150 were performed in 2010 in a quarry located in Cantabria, Spain. Cable sensors were used to register the forces, due to it was easy to place them (Figure 2), as there is no need to cut the ropes like in load cells. The sensor is able to measure the tension force of the cable indirectly. In the initial position, the cable is unaligned, and it is supported in 3 points: the external supports and the central removable flange. When the cable is tensioned, it tends to reach the alignment, so the beam bends. The beam should be tensioned in the lower face and compressed in the upper face. Inside the beam there are strain gauges which are able to measure the deformation. The deformation of the gauges and the tension force of the cable is correlated and can be calibrated using a universal tension machine. Ten cable sensors were placed, four in the perimeter cables, four in the upstream cables and two in the cable net. Two high-speed cameras were used to determine the maximum displacement. IBT-500 was tested in 2015 in a different quarry in Cantabria, Spain. In these tests the same sensor technology was used, as well as fourteen cable sensors were used: four on the perimeter cables, two on the right upstream cables, four on the side cables and four in the cable net.

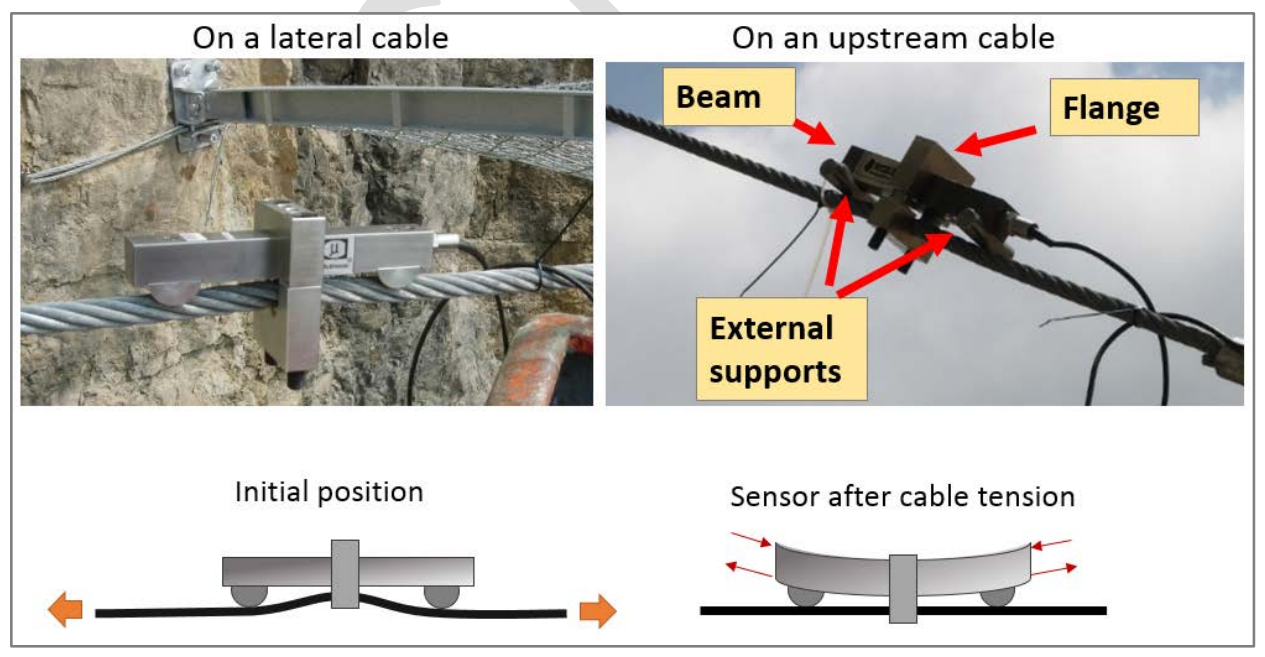

Figure 2. Positioning and working scheme of the cable sensors.

Blocks used in the tests had a polyhedron shape as detailed in the ETAG-027.

Energy and block characteristics are detailed in Table 1. 
Table 1. Properties of the blocks used in the ETAG 027 tests.

\begin{tabular}{|c|c|c|c|c|c|}
\hline Barrier type & Test type & Mass $(\mathrm{kg})$ & Velocity $(\mathrm{m} / \mathrm{s})$ & Energy $(\mathrm{kJ})$ & Lext $(\mathrm{m})$ \\
\hline \multirow{2}{*}{ IBT-150 } & $1^{\text {st }}$ and $2^{\text {nd }}$ SEL & 148 & 26 & 50 & 0.44 \\
\cline { 2 - 6 } & MEL & 504 & 25.6 & 165 & 0.67 \\
\hline \multirow{2}{*}{ IBT-500 } & $1^{\text {st }}$ and $2^{\text {nd }}$ SEL & 460,5 & 27 & 167 & 0.65 \\
\cline { 2 - 6 } & MEL & 1429,5 & 27 & 521 & 0.95 \\
\hline
\end{tabular}

Both barriers passed the tests successfully. None of the cables suffered higher loads than their ultimate load (breaking load), as it can be seen in Figure 3 and Figure 4. Signal processing with a Savitzky-Golay filter was used to remove signal noise coming out in all the experimental load history graphs.
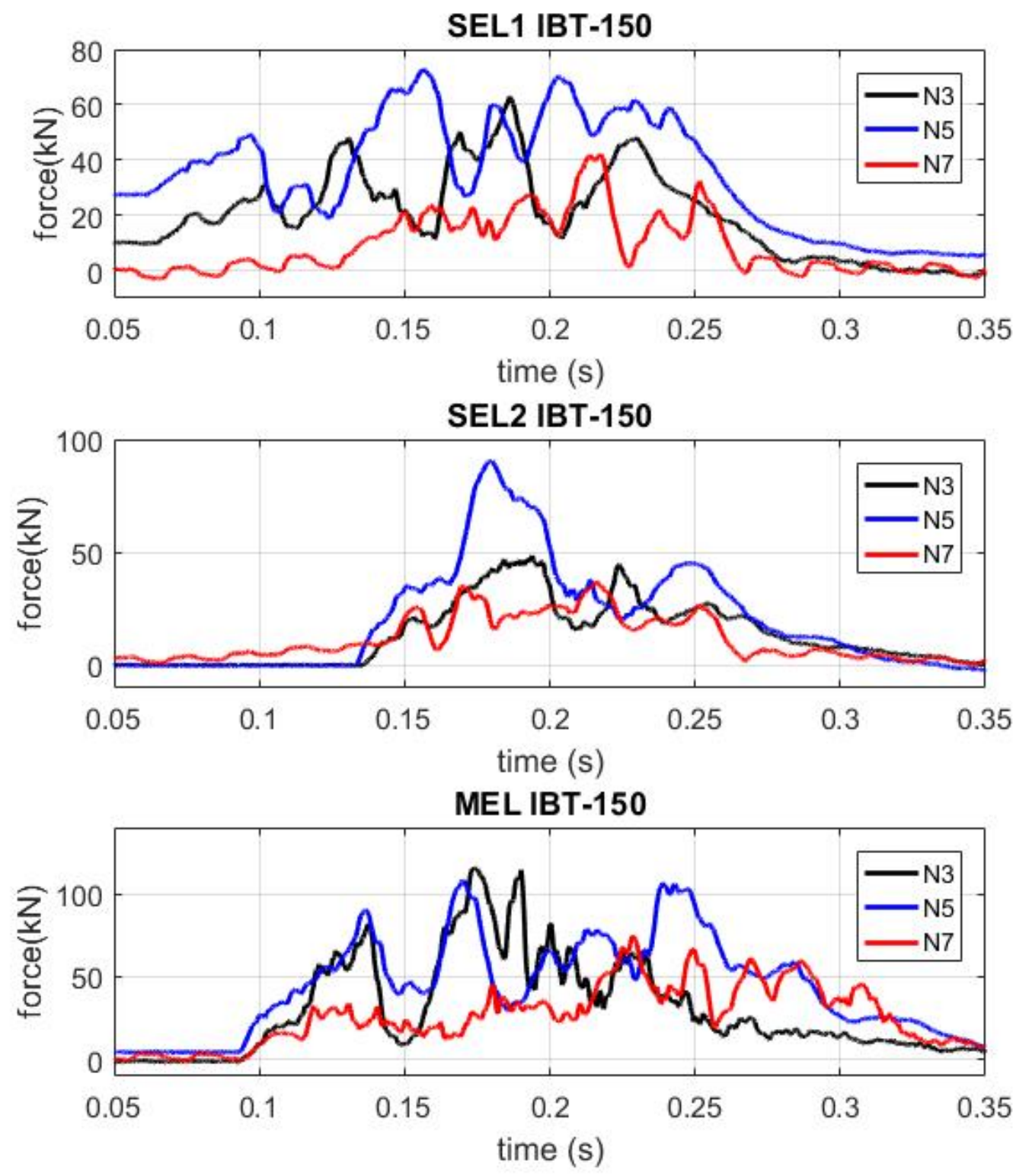

Figure 3. Loads register of perimeter, side and upstream cables at: a) $1^{\text {st }}$ SEL test IBT150, b) $2^{\text {nd }}$ SEL test IBT150 and c)MEL test IBT150 
In the first impact, barrier IBT150 suffered loads up to $72 \mathrm{kN}$. Its most load-demanded component was the perimeter cable passing through the free posts ends, and the peak load was located at the central module. In the second impact of the SEL test, a load of $91 \mathrm{kN}$ was registered in the same perimeter cable, whereas the rest of the cables had a maximum force of $51 \mathrm{kN}$, a lower value than the expected as a result of a slight deviation of the block. Although the impact was not exactly in the center, it was inside the delimited margins mentioned in the ETAG. At last, MEL test induced the higher load values in the cables, reaching a maximum of $111 \mathrm{kN}$ in the perimeter cable next to the slope.
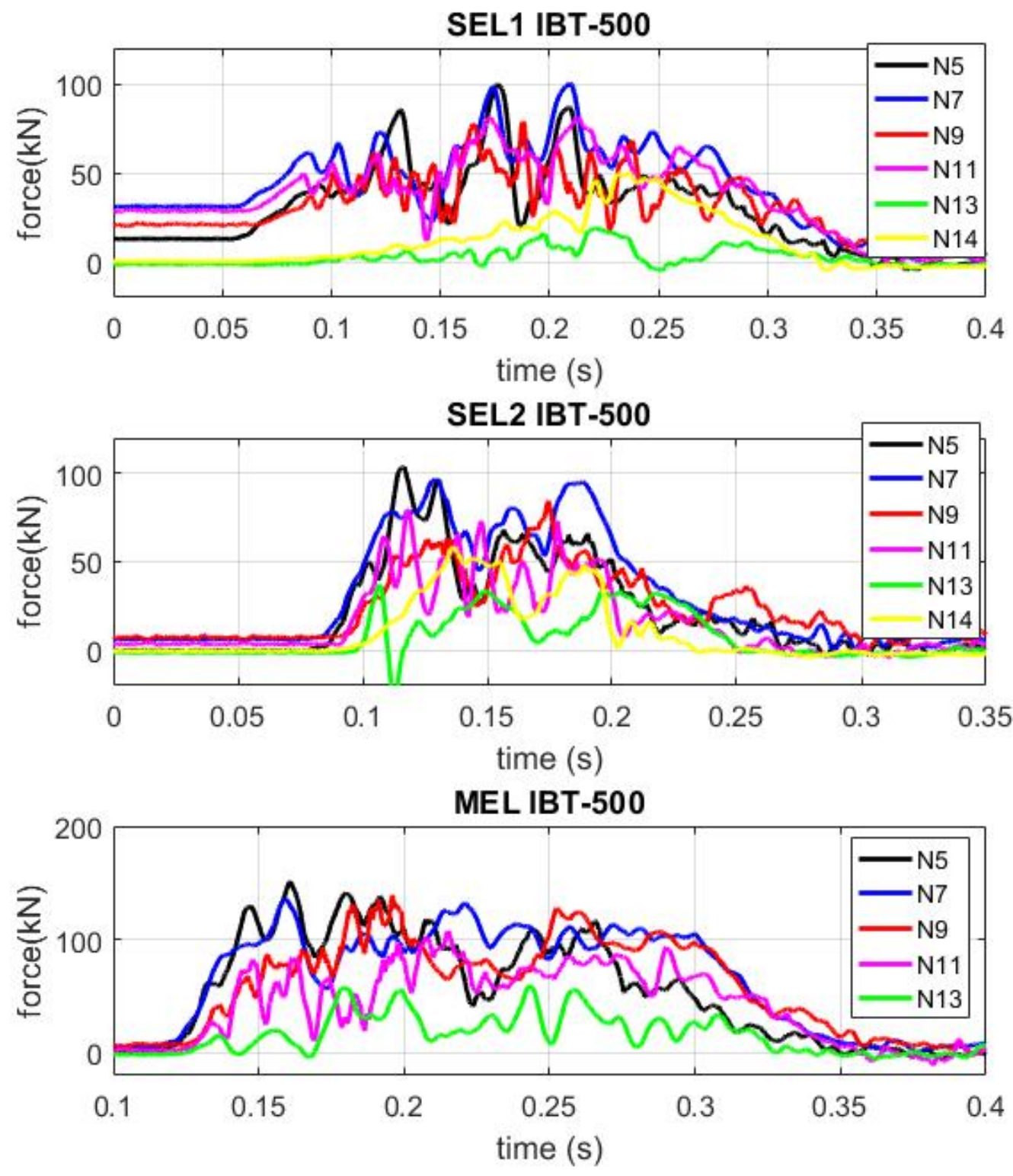

Figure 4. Loads register of perimeter, side and upstream cables at: a) $1^{\text {st }}$ SEL test IBT500, b) $2^{\text {nd }}$ SEL test IBT500 and c) MEL test IBT500 
With the first SEL impact on IBT500, sensors located on the perimeter cables at the central module (N5 and N7) registered a maximum load of $100 \mathrm{kN}$. Upstream cables were the less loaddemanded components, with a maximum of $50 \mathrm{kN}$ in N14. In the second SEL impact, the braking time was lower, whilst the values of peak loads were almost the same as in the first SEL. Finally, MEL test induced loads on perimeter cables around $150 \mathrm{kN}$. Sensor N14 broke during MEL test, so no results were extracted at this point from the barrier.

For both barriers, only force of sensors located in the left part of the perimeter and lateral cables are shown in both barriers since the symmetric ones present similar force registration along time, as it can be seen in Figure 5 for two of the symmetric points of IBT- 500 for a MEL impact.
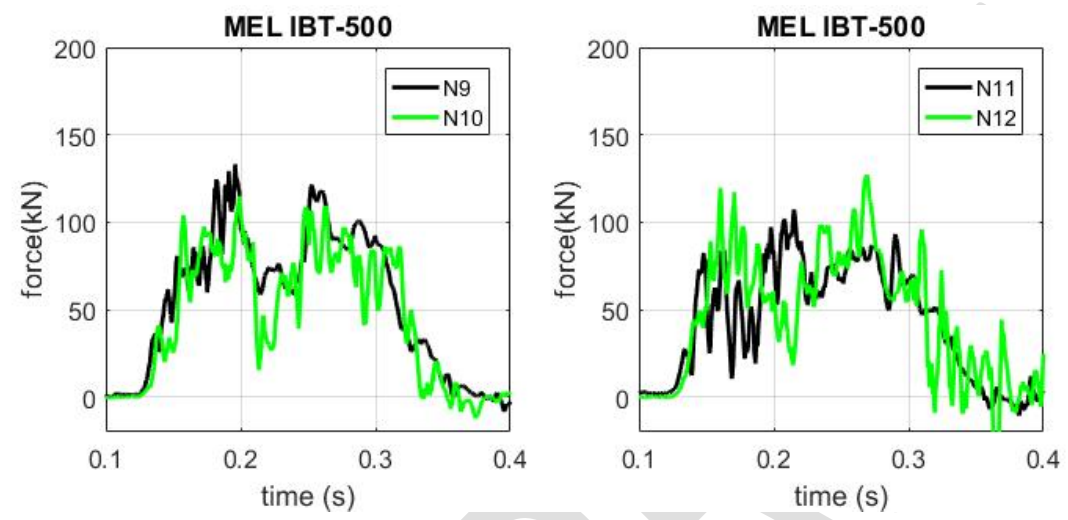

Figure 5. Load register of sensors located in symmetric positions for MEL of barrier IBT-500

In other types of barriers, in which the interception structure is connected to the perimeter cables with shackles, a phenomenon called curtain effect takes place [18]. This means that these shackles can slide through the perimeter cables towards the impact zone to allow the net to displace together with the block. This generally implies a higher elongation, but also increases the braking time, and hence, reduces the maximum loads suffered by the structure. Although the connection in IBT-150 and IBT-500 is attained by a sewing cable, it does not mean it is a rigid connection, since the curtain effect also takes place. This is evidenced by Figure 6, where the net moved to the center of the impact module-the block had already been removed-, as the vertices of the squares are more grouped in the central part than in the laterals.

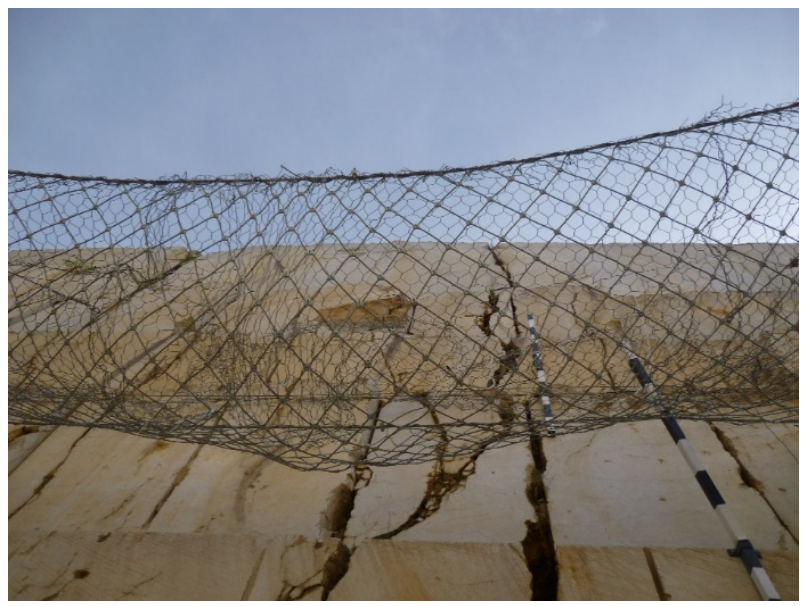

Figure 6. Displacement of the net towards the impact point evidencing some curtain effect. 


\section{Validation of the numerical models}

\subsection{Details of the FE models}

With the aim of using a numerical model that truly represents the behavior of the barrier, the two barriers are simulated and compared with the results of the experimental tests.

An explicit analysis was carried out. This type of analysis is the most suitable to face non linearities as well as highly dynamic events. Non linearities arise due to three facts: friction contacts, material plasticity and geometry non-linearity. The FE models in which this paper is focused experience all of them simultaneously.

Cables were simulated using truss elements, namely, 1D elements without flexural rigidity. Mechanical properties of the materials are indispensable input for the FE models. For this reason, a series of tensile tests were carried out to determine the stress-strain curves of the cables following the procedure established by the ASTM E21 Standard [19]. Three samples were available with nominal diameters of 8,16 and $22 \mathrm{~mm}$. The tests were performed by means of a Universal Instron 8500 testing machine, with a loading capacity of $250 \mathrm{kN}$, under control of displacements conditions at a fixed strain rate of $10^{-3} \mathrm{~min}^{-1}$. The results can be seen in Figure 7 .

The explicit-FEM model was built considering the elastic-plastic material response. To this end, the stress-strain curves, experimentally obtained, were implemented using a multilinear elasticplastic law. When the cables are loaded they initially respond elastically until they reach the material yield stress; then, the plastic regime occurs. Next, when the cables are unloaded, the material follows a linear path with a slope given by the elastic modulus (E). Hence, part of the strain is non-recoverable $\left(\varepsilon_{p l}\right)$ and, in a hypothetical loading of the cable, it would develop a lower total strain until failure and a higher yield stress, this phenomenon being known as strain hardening. Even though no repetitive loadings were applied, the explicit-FEM model would be able to reproduce them (without loss of generality, strain hardening was modelled as kinematic). A ductile damage criterion with a linear evolution is defined to ensure the correct behavior of the barrier. A linear softening law was used and the displacement at failure was set to 10-6 $\mathrm{m}$ in all the cables in order to ensure their immediate breakage after reaching the ultimate stress. The transformation process of the Load-strain curves to use them as an input for the software is explained in the following diagram of Fig. 8. Equivalent area of cables is detailed in Table 2, and values of material properties are included in Table 3.

Table 2. Equivalent area of the cables

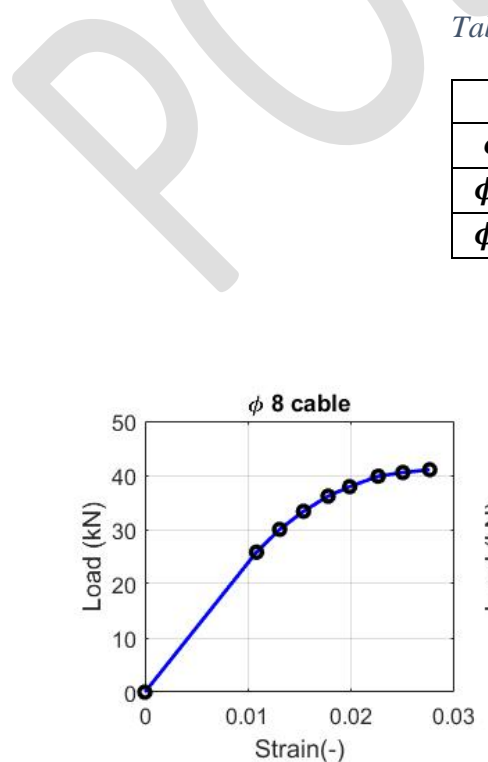

\begin{tabular}{|c|c|}
\hline & Equivalent area $\left.\mathbf{( m m}^{\mathbf{2}}\right)$ \\
\hline $\boldsymbol{\phi 8}$ & 28 \\
\hline $\boldsymbol{\phi 1 6}$ & 111 \\
\hline $\boldsymbol{\phi 2 2}$ & 227 \\
\hline
\end{tabular}

Figure 7. Original characteristic curve force-strain of the cables. 
The transformation process of the Load-strain curves to use them as an input for the software is explained in the following diagram of Figure 8.

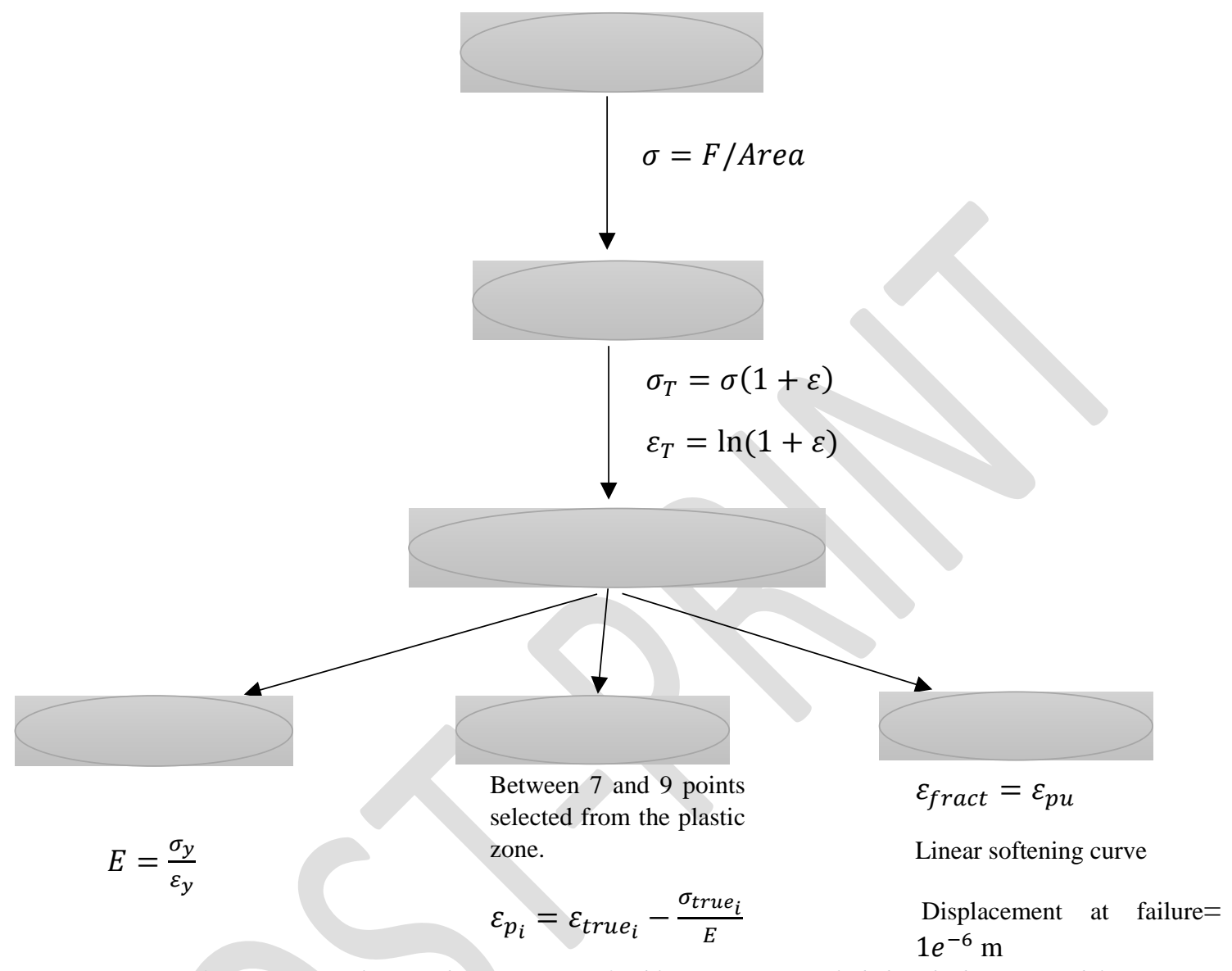

Figure 8. Diagram explaining the attainment of cable parameters included in the barrier models.

The samples tested were provided by the supplier of these barriers. The differences in terms of stress and strain among samples might be related with the strength of the steel strands as well as the manufacturing process, since the cables were not provided by the same company.

Table 3. Parameters used in the definition of the material behavior of the cables

\begin{tabular}{|c|c|c|c|c|c|c|}
\cline { 2 - 6 } \multicolumn{1}{c|}{} & \multicolumn{2}{c|}{ Cable d8 } & \multicolumn{2}{c|}{ Cable d16 } & \multicolumn{2}{c|}{ Cable d22 } \\
\hline \multirow{2}{*}{$\begin{array}{c}\text { Elastic } \\
\text { Behavior }\end{array}$} & \multicolumn{2}{c|}{ Young Modulus (MPa) } & \multicolumn{2}{c|}{ Young Modulus (MPa) } & \multicolumn{2}{c|}{ Young Modulus (MPa) } \\
\cline { 2 - 7 } & \multicolumn{2}{|c|}{85864} & \multicolumn{2}{c|}{75792} & \multicolumn{2}{c|}{98901} \\
\hline \multirow{5}{*}{$\begin{array}{c}\text { Plastic } \\
\text { behavior }\end{array}$} & $\begin{array}{c}\text { Plastic log strain } \\
(-)\end{array}$ & $\begin{array}{c}\text { True stress } \\
(\mathrm{MPa})\end{array}$ & $\begin{array}{c}\text { Plastic log strain } \\
(-)\end{array}$ & $\begin{array}{c}\text { True stress } \\
(\mathrm{MPa})\end{array}$ & $\begin{array}{c}\text { Plastic log } \\
\text { strain (-) }\end{array}$ & $\begin{array}{c}\text { True stress } \\
(\mathrm{MPa})\end{array}$ \\
\cline { 2 - 7 } & 0.0000 & 932 & 0.0000 & 1007 & 0.0000 & 918 \\
\cline { 2 - 7 } & 0.0003 & 1086 & 0.0012 & 1254 & 0.0003 & 1174 \\
\cline { 2 - 7 } & 0.0012 & 1210 & 0.0026 & 1432 & 0.0007 & 1288 \\
\cline { 2 - 7 } & 0.0023 & 1314 & 0.0048 & 1618 & 0.0015 & 1402 \\
\cline { 2 - 7 } & 0.0036 & 1381 & 0.0080 & 1720 & 0.0028 & 1497 \\
\cline { 2 - 7 } & 0.0054 & 1455 & 0.0121 & 1820 & 0.0042 & 1561 \\
\hline
\end{tabular}




\begin{tabular}{|c|c|c|c|c|c|c|}
\hline & 0.0074 & 1483 & 0.0160 & 1867 & 0.0062 & 1616 \\
\hline & 0.0097 & 1506 & 0.0209 & 1891 & 0.0082 & 1652 \\
\hline \multirow{4}{*}{ Damage } & \multicolumn{2}{|c|}{ Fracture strain } & \multicolumn{2}{|c|}{ Fracture strain } & \multicolumn{2}{|c|}{ Fracture strain } \\
\hline & \multicolumn{2}{|c|}{0.0097} & \multicolumn{2}{|c|}{0.0209} & \multicolumn{2}{|c|}{0.0082} \\
\hline & \multicolumn{2}{|c|}{ Displacement at failure $(\mathrm{m})$} & \multirow{2}{*}{\multicolumn{2}{|c|}{ Displacement at failure $(\mathrm{m})$}} & \multirow{2}{*}{\multicolumn{2}{|c|}{ Displacement at failure $(\mathrm{m})$}} \\
\hline & \multicolumn{2}{|c|}{0.000001} & & & & \\
\hline
\end{tabular}

The real connection between the perimeter cables and the square cable net was attained through an additional cable rolled around the perimeter cable crossing each lateral square of the net, and fixed in both side ends of the barrier (Figure 9). Due to the complexity of the numerical modeling of the sewing cable that would imply larger computational costs, this connection was simplified using circular shackles which connect each lateral vertex of the grid of the net with the perimeter cable. The shackles were modeled with rigid circular 1D elements. Like the real sewing in the barriers, the first square after the central posts was not linked to the perimeter cable.

a)

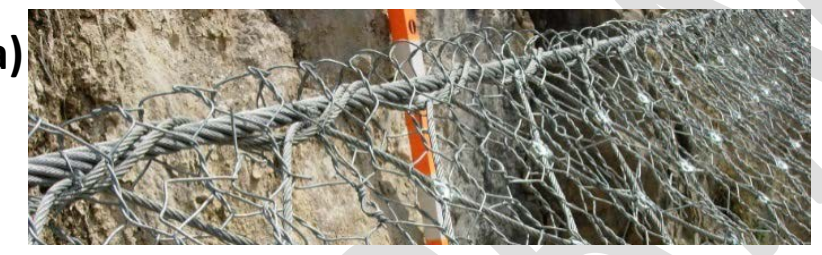

b)

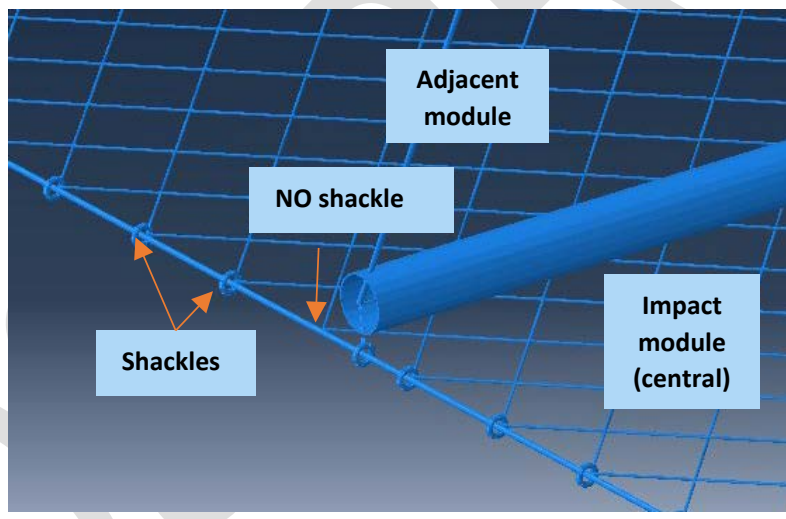

Figure 9. Connection between the cable net to the perimeter cables a) Real sewing of the net through an auxiliary cable, and b) Numerical representation of the sewing using imaginary shackles. The square of the net immediately after the posts is not connected to the perimeter cable.

The posts were simulated using beam elements with the real profile geometry. A bilinear elastoplastic material was assigned to the posts. A Young Moduli of $210 \mathrm{GPa}$ was used. The plastic slope was defined by two points, the first one defining the yield stress of $275 \mathrm{MPa}$ with a zeroplastic strain, and the second one defining the ultimate stress of $455 \mathrm{MPa}$ with a plastic strain of 0.2. The failure of the post is included by using the same damage model as in the cables. The displacement at failure was set to $10^{-6} \mathrm{~m}$. In both ends of the posts, they have a steel component with a geometry that is able to guide the perimeter cables and keep the net erected. These parts were also simplified using the same rigid shackles, merged to the post with a Join connection. The square net was fixed to the extreme posts by coupling all degrees of freedom in each vertex of the net (Figure 10). 


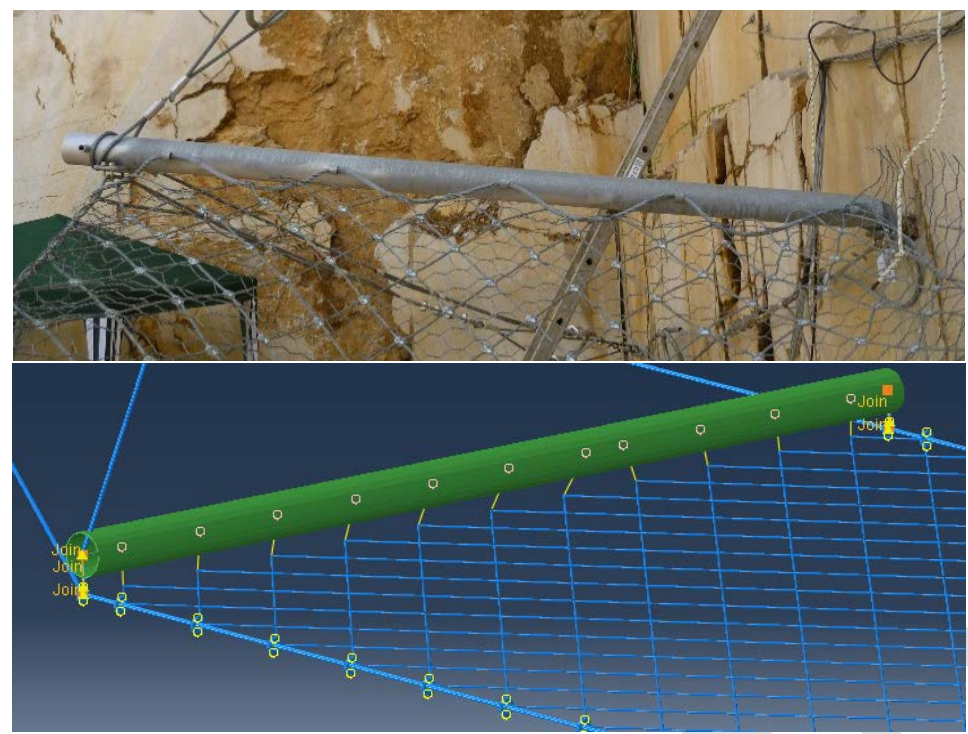

Figure 10. Link between the cable net and the outermost posts through the coupling of their degrees of freedom.

A general contact approach was used between all the components of the barrier, that is, between the block and the net and between the shackles and the perimeter cables. Penalty method was implemented and several values of friction coefficients were checked.

A friction coefficient of 0.4 was used between the block concrete and the cable net, as previously reported by other authors (see [5] and [9]). Three different values of friction coefficients -0.2, 0.4 and 0.6- between the perimeter cables and the shackles were employed. A coefficient of 0.6 resulted in a very stiff behaviour of the barrier with a premature failure of the structure. In contrast, a value of 0.2 caused an excessive curtain effect that has not been experimentally observed. A coefficient of 0.4 was determined as the most accurate. The contact between shackles in the posts and the perimeter cables was also checked using a friction coefficient between 0.2 and 0.4 ; a value of 0.2 was selected since it does not create stress concentration in the cables that go through the shackles connected to the posts.

The way of application of the interaction was the following: A general friction interaction was applied to the whole model. Penalty method was included in the tangential behavior, with a friction coefficient of 0.4. A hard contact approach reproduced the normal behavior. Individual property assignments were specified between post shackles and perimeter cables applying a specific friction coefficient of 0.2 .

The energy dissipation devices were implemented using axial connectors with a behavior law of the Figure 11. More information about this kind of brakes can be found in [20]. This shape of the brakes modelling (curves) was picked because there is interest in including the effect of the nonuniform sliding of the sleeves in these devices, which triggers these two peaks before its complete extension. This effect has a great influence on the final Load-Time curves. 


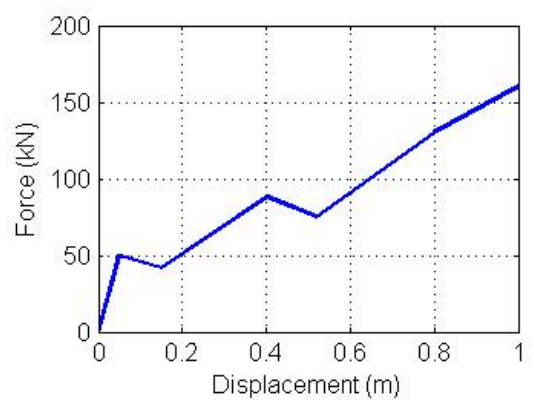

Figure 11. Force-Displacement behavior curve of the energy dissipation devices in all the barrier models performed.

The concrete blocks were modeled as analytic rigid bodies with the same geometry than the experimental test (refer to Table 1).

The model was divided into 3 steps. In the first time interval, of 1 second, the acceleration of gravity $(9.81 \mathrm{~m} / \mathrm{s} 2)$ was imposed to all the elements of the barrier in order to provide the barrier with its sag-shape; moreover, pretension was applied to the lateral cables (only in the SEL model). In the second step, of $0.003 \mathrm{~s}$, the initial velocity (Table 1) was applied to the blocks, which were located some millimeters above the barrier. Finally, in the third step, with a duration of 0.6 seconds, gravity was added to the block and the impact was simulated.

A general view of the FE model of IBT-500 can be seen in Figure 12, while Table 4 collects all the model properties.

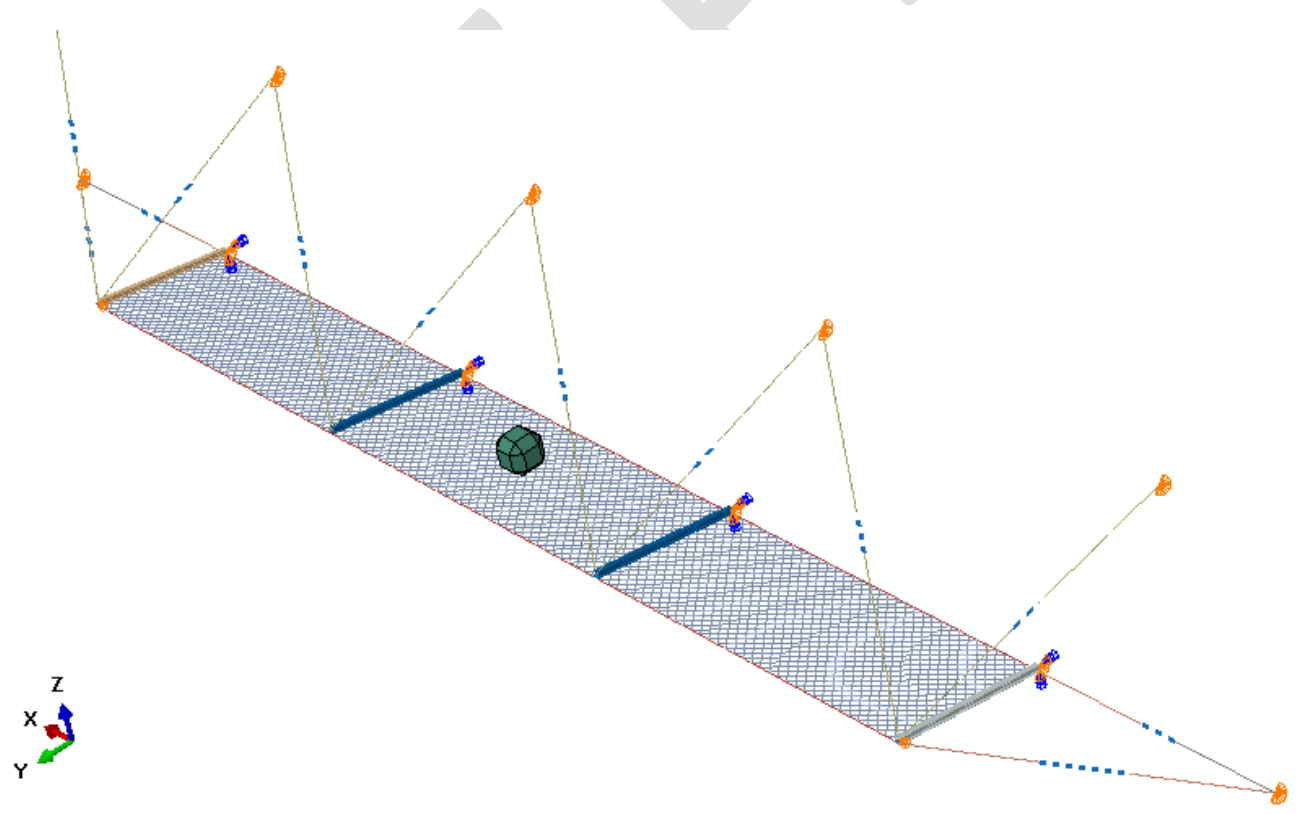

Figure 12. Final appearance of the barrier IBT-500. 
Table 4. Model parameters used in both barriers IBT-150 and IBT-500

\begin{tabular}{|c|c|}
\hline Feature & Approach \\
\hline Solver type & Explicit \\
\hline Steps & $\begin{array}{l}\text { 1-Gravity on the barrier and pretension (1 s) } \\
\text { 2-Initial velocity of the block }(0.003 \mathrm{~s}) \\
\text { 3-Gravity to the block and impact }(0.6 \mathrm{~s})\end{array}$ \\
\hline Material type & $\begin{array}{l}\text { Cables: multilinear elastic-plastic model with damage } \\
\text { Posts: multilinear elastic-plastic model with damage } \\
\text { Block: rigid body } \\
\text { Shackles: rigid bodies }\end{array}$ \\
\hline Brakes & Axial connector Force-displacement law \\
\hline
\end{tabular}

\subsection{Results}

Numerical results of the first launch of the SEL test and of the MEL test in barriers IBT150 and IBT500 are compared in Figures 13-16. Blue dotted lines show the results of force from the numerical simulations in the same location of the sensors. The force registration of the sensors in the experimental tests are plotted with black lines.

Cable load cells were the only sensors used to compare actual values in the test versus numerical simulations. Strain gauges in foundations (adhered on top and bottom bolts generatrix) were not considered since their values were unrealistically low. In addition, its realistic implementation in the numerical model was not represented since it was not considered a key point of the overall kit. ETAG-27 stablishes that is compulsory to measure the action on the foundations, however, it does not specify how and where to measure. Since each kit has its own foundation system, it is also difficult to stablish what element is part of the foundation and what element is part of the post. In this type of dynamic barrier, it was considered that the foundations were the bolts anchored to the ground. The plate that links the post to the foundation is just considered a connection element. Since the location of the plate (in direct contact with the whole rock wall surface) does not allow the bolt to hardly bend, then, the values of strains in the bolts are nearly neglectable. For a proper monitoring of the reaction forces in the foundations, a complicated intermediate element to monitor the forces in the three directions should be developed, as in [21] Nevertheless, ETAG 27 also established that for dynamic barriers that use upstream cables it is not necessary to monitor forces on foundations.

Due to contact related difficulties when reloading the same barrier after one impact, second impact SEL was not reproduced, and MEL impact was simulated with a new undeformed barrier model. Some differences are expected to be found related with the total time of the MEL impact since, observing Figure 3 and Figure 4, the effect of consecutive impacts stiffens the whole structure. Despite this fact, comparison in a MEL impact can give a good idea of the maximum forces because SEL impacts does not induce to plasticity in the cables, and the brakes are far from ending their dissipation mechanism. 

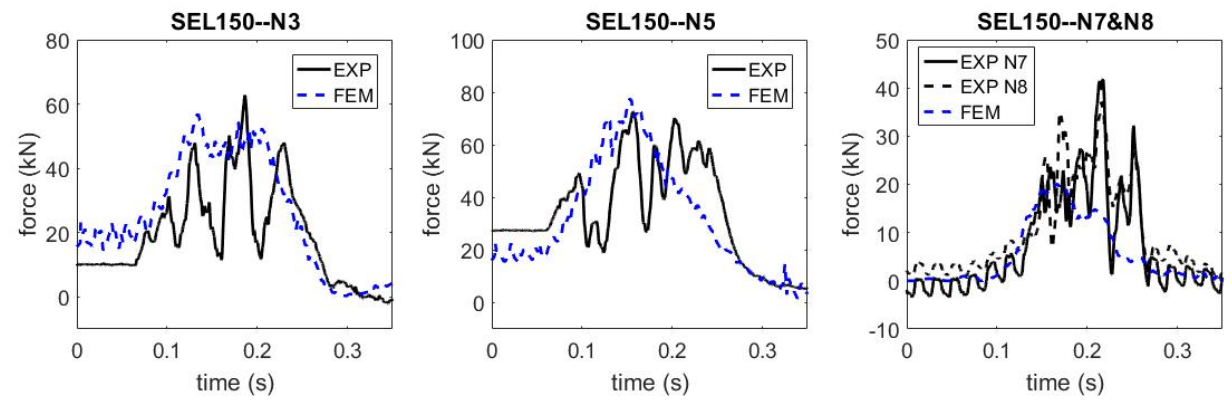

Figure 13. Comparison of the numerical and experimental results of the SEL test in barrier IBT-150.
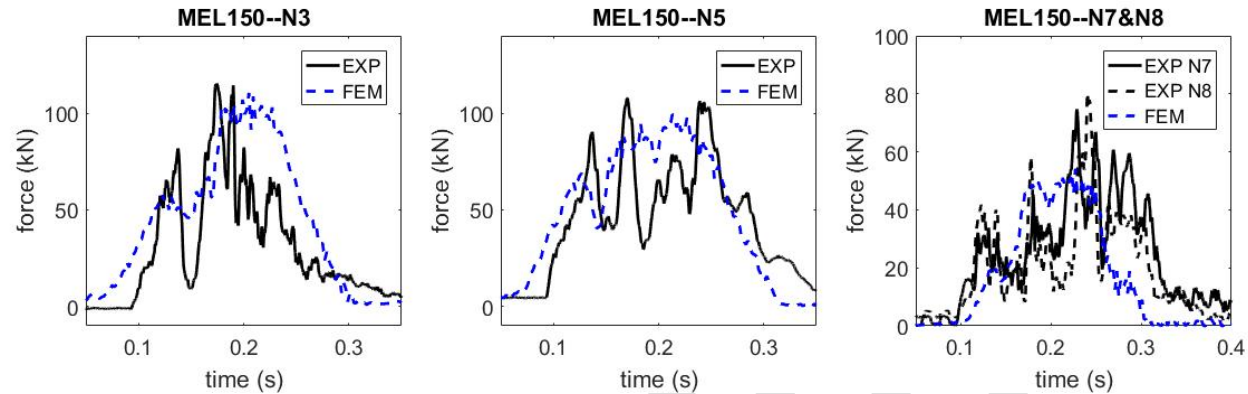

Figure 14. Comparison of the numerical and experimental results of the MEL test in barrier IBT-150.
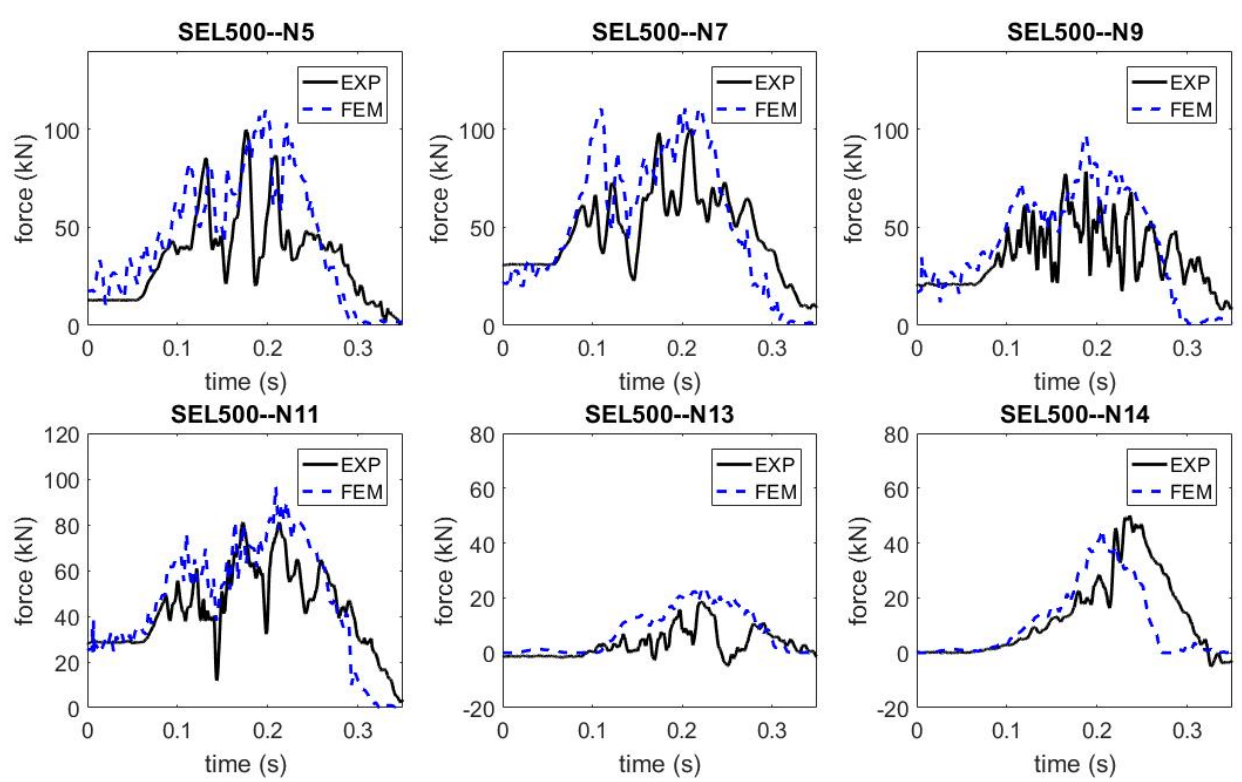

Figure 15. Comparison of the numerical and experimental results of the SEL test in barrier IBT-500 

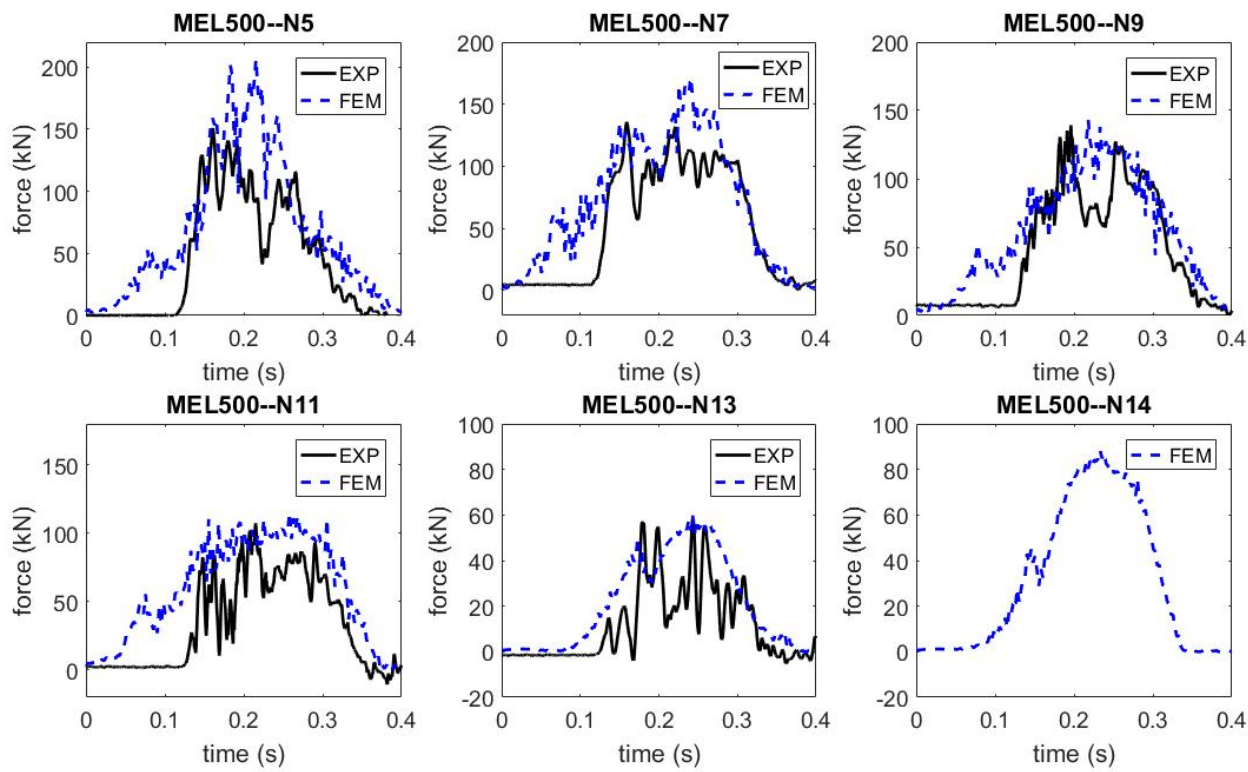

Figure 16. Comparison of the numerical and experimental results of the MEL test in barrier IBT-500

As said in the previous section, sensor N14 of IBT500 (Figure 16) was damaged in the last impact of the IBT500 test, so only numerical results are presented.

In general, explicit-FEM load histories show a good correspondence with the experimental loads from the SEL and MEL tests. Differences in the fittings of sensors located in upstream cables of IBT150 (N7 and N8 on Figure 13 and Figure 14) may be due to the experimental behavior of the brakes, which can develop a different Force-Displacement paths even having the same sleeve pressure [20]. The major disagreements are found the perimeter cable of IBT500 closest to the slope (N5 on Figure 16), where a higher value of loads are registered in the explicit-FEM model. This could be related to the loosing of the sewing cable around the post that happens in the real barrier test, lowering the stress concentration of the perimeter cables in the central module. On the contrary, the model developed in this work has a simplified method for connecting the net to these cables, and does not account for this behavior. The only way to reduce stress concentration is by means of the failure of the cable squares attached to the shackles next to the post ends when they overcome its maximum stress.

In both barriers, maximum elongation was only compared for the first SEL impact, since the MEL test elongation is affected by permanent deformation of the two previous SEL impacts. Results are shown in Figure 17. A maximal dispersion between experimental and numerical results is $8 \%$.

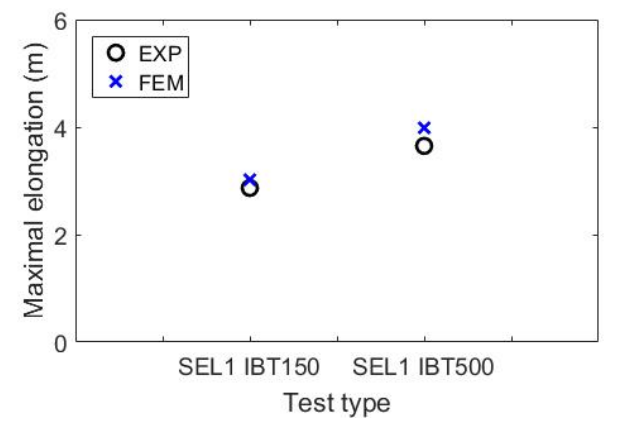

Figure 17. Maximal elongation of SEL1 tests. Numerical and experimental results. 
All the data supplied above show the reliability of the models (material definitions, connections, friction contact) in the sense that they give a real response of the dynamic behavior of a flexible barrier due to a rock impact.

The calculations were carried out in a machine with 2 processors Intel Xeon E5630 2,53GHz. The computational cost of the IBT150 was 32 minutes, and for the model of IBT500 this time was 43 minutes. Differences are related with the highest number of elements of the second barrier with respect to the first one.

\section{Analysis of the requirement of brakes in IBT150}

The barrier IBT-150 can be classified into the so called "low energy barriers". Some of this kind of barriers do not have upper cables, but posts rigidly fixed to the anchorage plates, that is, with all degrees of freedom restricted. Others, however, have upstream cables, and most of them do not include brake devices. The lower energy barriers can also include elastic brakes [1, 22]. A summary of low energy barriers of several manufacturers is shown in Table 5.

Table 5. Properties of low energy barriers of some manufacturers.

\begin{tabular}{|c|c|c|c|c|c|}
\hline \multirow{2}{*}{ Company } & Barrier model & $\begin{array}{c}\text { Anchorage to } \\
\text { post connection } \\
\text { type }\end{array}$ & $\begin{array}{c}\text { Brakes in side } \\
\text { cables }\end{array}$ & $\begin{array}{c}\text { Upstream } \\
\text { cables }\end{array}$ & $\begin{array}{c}\text { Brakes in } \\
\text { upstream } \\
\text { cables }\end{array}$ \\
\hline \multirow{3}{*}{ GeoBrugg } & RXE-500 & Hinge & Yes & Yes & No \\
\cline { 2 - 6 } & GBE-100-AR & Fixed & No & Yes & No \\
\cline { 2 - 6 } & GBE-500-A & Hinge & Yes & Yes & No \\
\hline Maccaferry & CTR 05/07/B & Hinge & Yes & Yes & No \\
\hline \multirow{2}{*}{3 GS GeoTech } & $3 \mathrm{~S}-100 \mathrm{E}$ & Fixed & Elastic & No & No \\
\cline { 2 - 6 } & $3 \mathrm{~S}-150 \mathrm{E}$ & Hinge & Elastic & Yes & No \\
\hline \multirow{2}{*}{$\begin{array}{c}\text { Rockfall } \\
\text { Defence }\end{array}$} & $100 \mathrm{~kJ}-\mathrm{a}$ & Fixed & Yes & Yes & Yes \\
\cline { 2 - 6 } & $100 \mathrm{~kJ}-\mathrm{b}$ & Fixed & Yes & Yes & No \\
\hline
\end{tabular}

In IBT-150, sensors N7 and N8 (Figure 14), corresponding to one of the upper cables certify that the maximum measured value is around $50 \%$ of the maximum cable capacity. The extension of all the brakes in the numerical MEL impact are obtained and summarized in Table 6, which corroborates that all of them, especially the ones located at the upstream cables, are underused considering that their maximum elongation is around 1 meter.

Table 6. Elongation of the brakes in a MEL test on IBT-150.

\begin{tabular}{|c|c|}
\hline Brake position & Elongation (m) \\
\hline F1 & 0.54 \\
\hline F2 & 0.42 \\
\hline F3 & 0.04 \\
\hline F4 & 0.35 \\
\hline F5 & 0.35 \\
\hline F6 & 0.03 \\
\hline F7 & 0.42 \\
\hline F8 & 0.54 \\
\hline
\end{tabular}

This indicates that the removal of the brakes located in the upper cables is feasible while at the same time maintaining capacity of $150 \mathrm{~kJ}$. This is corroborated by a numerical simulation in 
which the numerical model of IBT-150 was used replacing the upper cables which incorporate the brakes with continuous cables of $16 \mathrm{~mm}$ diameter between the post and the slide.

The differences in terms of maximum elongation in the case with all the brakes and in the case with only lateral brake is of only $0.1 \mathrm{~m}$ (Figure 19). Three facts were observed in the model without upper brakes that caused such small difference. Firstly, brakes F2 and F7 suffered an extension 0.15 meters higher than in the model with all brakes, which means a higher total length of the perimeter cables and hence a higher elongation of the barrier. However, this extension increment is not enough to compensate the removal of the upper brakes. The second observation was that posts had a higher deformation. As a result, the free end of the posts-not the one fixed to the anchorage plate-, move towards the centre where the impact takes place allowing a higher displacement of the net to the impact zone. The distance between free ends of the posts in the model with all the brakes is $9.4 \mathrm{~m}$, whilst this measurement in the model without upper brakes is $9.1 \mathrm{~m}$. At last, rotation of the block is also a matter of interest. Although the block impacts both barriers with the same angle, the results obtained at the instant of maximum deflection are different, influenced by the extension of the upper brakes. In the original IBT150 (Figure 18a) the rotation of the block is $14^{\circ}$, whereas in the second model (Figure $18 \mathrm{~b}$ ) this value is $24^{\circ}$.

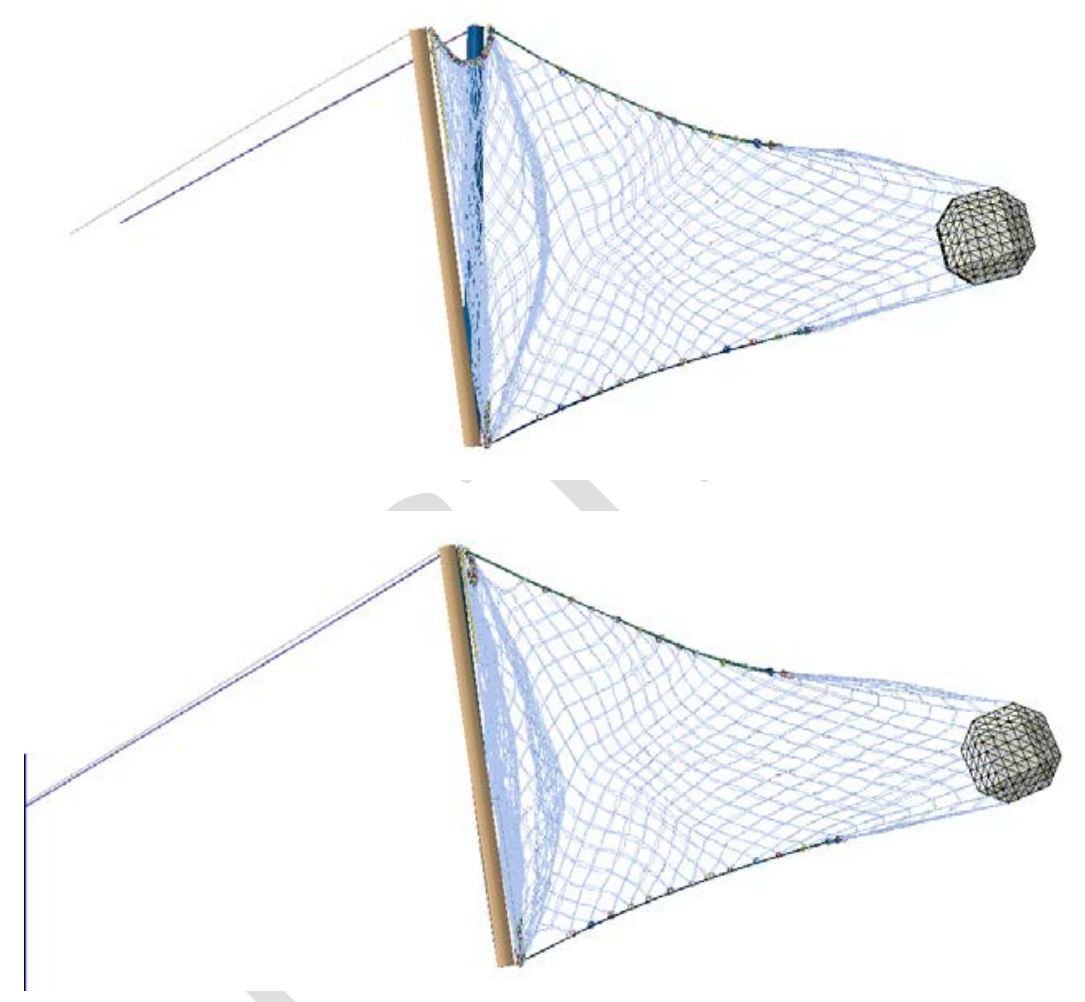

Figure 18. Lateral view of the numerical models a) with all the brakes (IBT-150) and b) without upper brakes.

Loads in perimeter cables were analyzed, as they are the most load-demanded parts of the structure. The maximum values were $100 \mathrm{kN}$ and $90 \mathrm{kN}$, which represent half of the ultimate load of these cables. This broad margin until failure suggests the possibility that a new numerical model removing all the brakes from the barrier could also resist the impact. In this new case, the maximum elongation is reached first, with a value of $3.5 \mathrm{~m}$, and has a lower braking time, of 0.195 seconds. Despite this shorter time of the impact, the structure resisted without any ruptures.

Differences of upstream force and elongation along the time for the three cases are shown in Figure 19. 

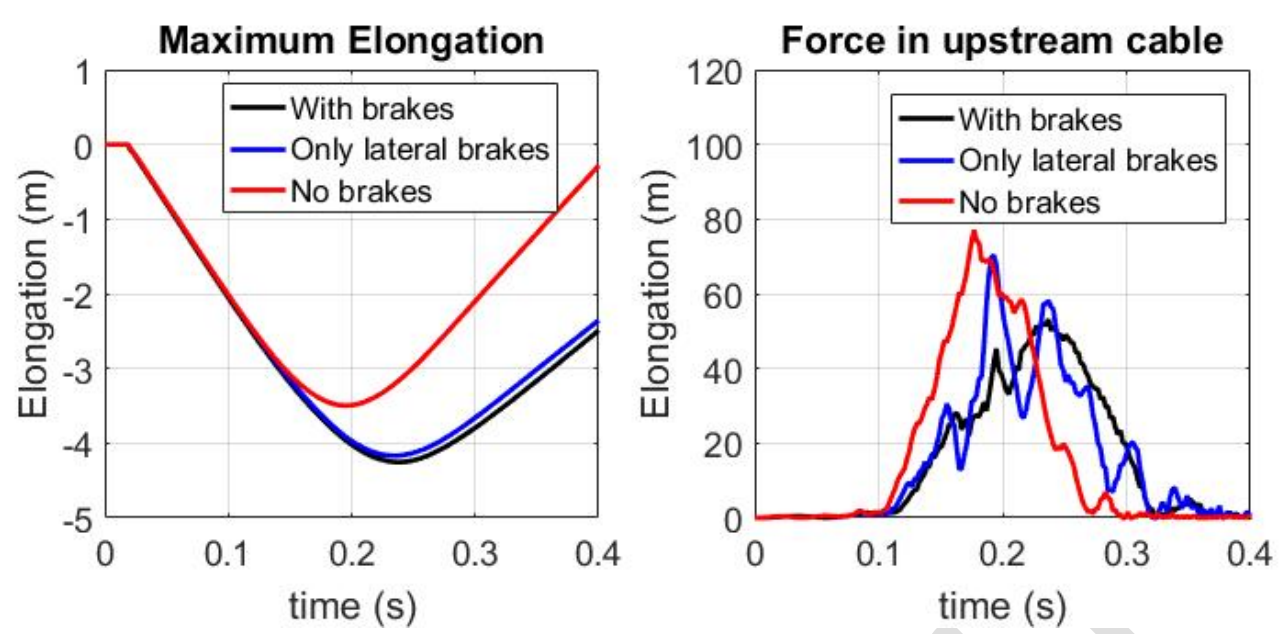

Figure 19. Force in one of the central upper cables and maximum elongation of the barrier models with and without the upper brakes.

With these two additional models in which some energy absorbing components are eliminated, it has been demonstrated that the IBT150 is overdimensioned for its energy aim. With the purpose of giving the manufacturer a realistic value of its energy retention capacity initial velocity is sequentially increased $1 \mathrm{~m} / \mathrm{s}$ until the barrier is not able to stop the rock. The kinetic energy of the block at the beginning of the last simulation performed without the break of any part of the barrier will be the critical MEL energy. The block used to perform these calculations was the same as the one of the MEL test of IBT150. Results indicate that the barrier IBT150 including brakes in all their upstream and lateral cables is able to retain up to $294 \mathrm{~kJ}$, reaching an Energy level classification 1 according to ETAG027 [17]. Beyond this energy level the perimeter cable next to the slope breaks around the post connection (Figure 20).

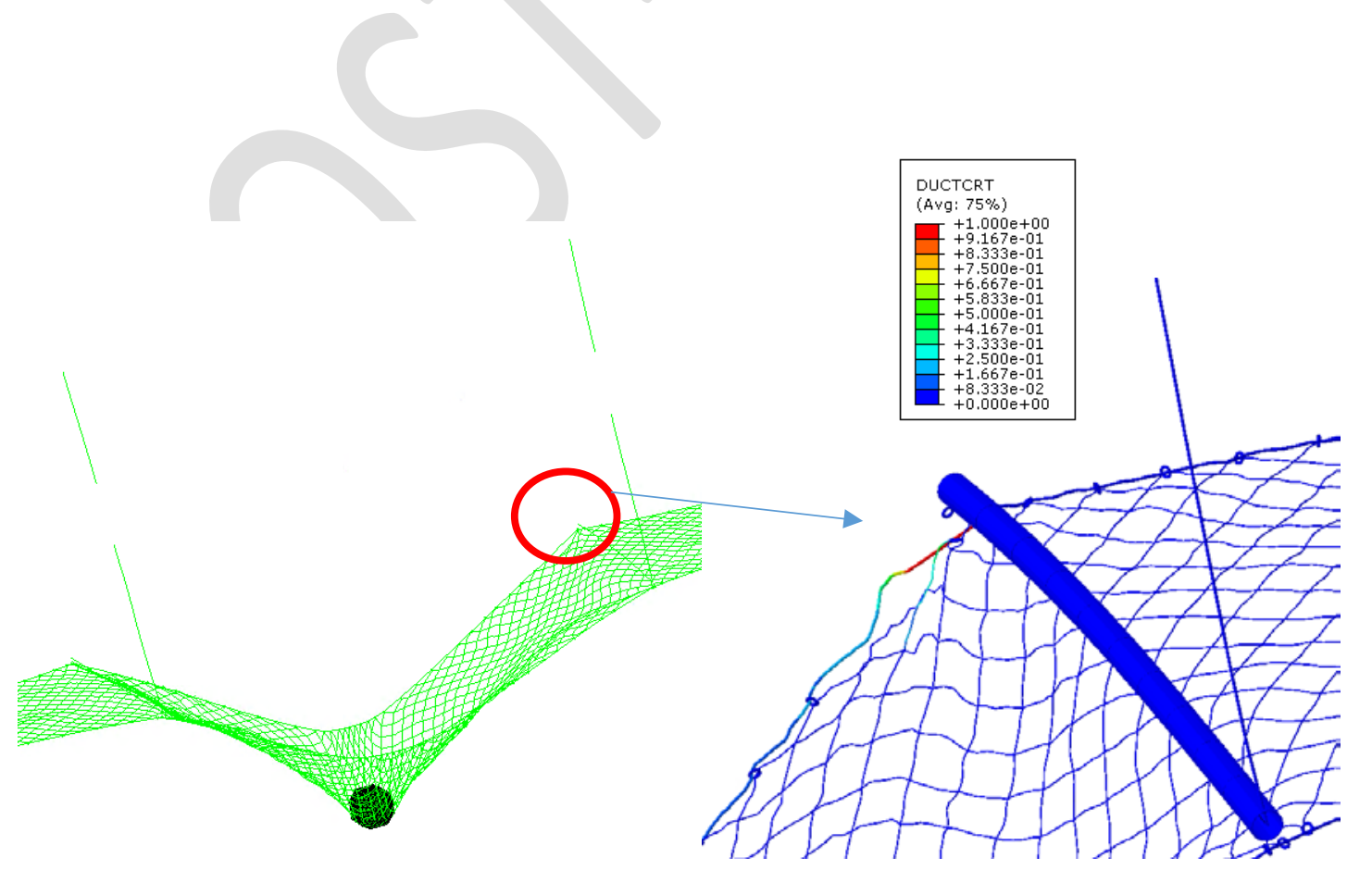

Figure 20. Failure in one of the perimeter cables of the original IBT-150 when looking for maximum energy retention capacity 
The same procedure was followed in the two modified barriers. Whilst the model without upper brakes retain $229 \mathrm{~kJ}$, the model without any brake fails with an energy of $172 \mathrm{~kJ}$. This value is excessively close to $150 \mathrm{~kJ}$, so the use of this barrier configuration for a $150 \mathrm{~kJ}$ aim is not recommended. In the first case, the weakest point of the structure was the net at the impact zone while in the second case it was the perimeter cable.

\section{Parametrical analysis of geometrical variables in the interception structure of IBT500}

Using the model of IBT-500 as reference, the value of four different geometrical parameters were varied in order to study their influence in the maximal retention energy.

Several factors regarding the location of the barrier sometimes force its geometrical modification with respect to the ETAG tested barrier. The availability of the terrain to insert the bolts with the anchorages and the horizontal distance to protect have an influence on the distance among posts. Moreover, the trajectory of the falling rocks affects the height of the barrier, mainly due to the rebounds against the slide. These two geometrical parameters change the energy retention capacity, and that is the reason for their investigation, making the distance among posts vary between 8 and $12 \mathrm{~m}$ (S5 and S6), and the height of the barrier between 2.5 and $6 \mathrm{~m}$ (S7 and S8) (see Table 7).

The two remaining parameters do not change the overall dimension of the barrier, but affect the net grid itself. One of the parameters is the size of the square grid, which has been studied in a static way in [22], but its influence in the maximum energy has not been analyzed dynamically by any author yet. Two models have been developed with grid dimensions of 150x150mm (S3) and $300 \times 300 \mathrm{~mm}$ (S4). Finally, the cable net dimension is also a matter of interest, and has been changed between 6 and $10 \mathrm{~mm}$ (S1 and S2).

Using a simple linear regression model, the influence of these variables on the response can be independently evaluated. For the sake of simplicity, the equation that represent this assessment method was chosen as a first degree polynomial, in which each term is related with each parameter. In the work presented, all the variables are fixed excepting one at each time, a similar behavior as getting a partial derivative of the polynomial with respect to each term of it.

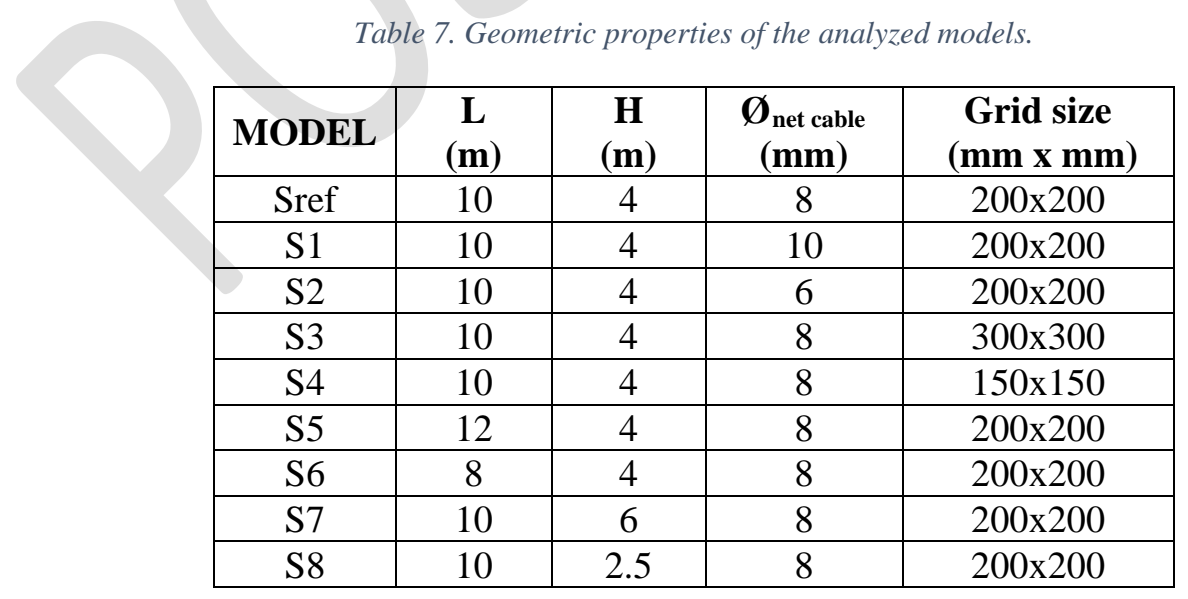

As in the previous section, the velocity is increased by $1 \mathrm{~m} / \mathrm{s}$ in each iteration until the block trespasses the barrier. The block that impacts in all the barrier models was the same as the used in the MEL impact of the IBT-500 (named reference model) with a $\mathrm{L}_{\text {ext }}$ of 0.95 and a weight of $1429 \mathrm{~kg}$. 
In all the models, the failure takes place on the net at the impact point (Figure 21), excepting S1 in which the barrier is not able to stop the block due to failure in one point on the perimeter cable close to the guiding shackle attached to the post (similar failure than in Figure 20).

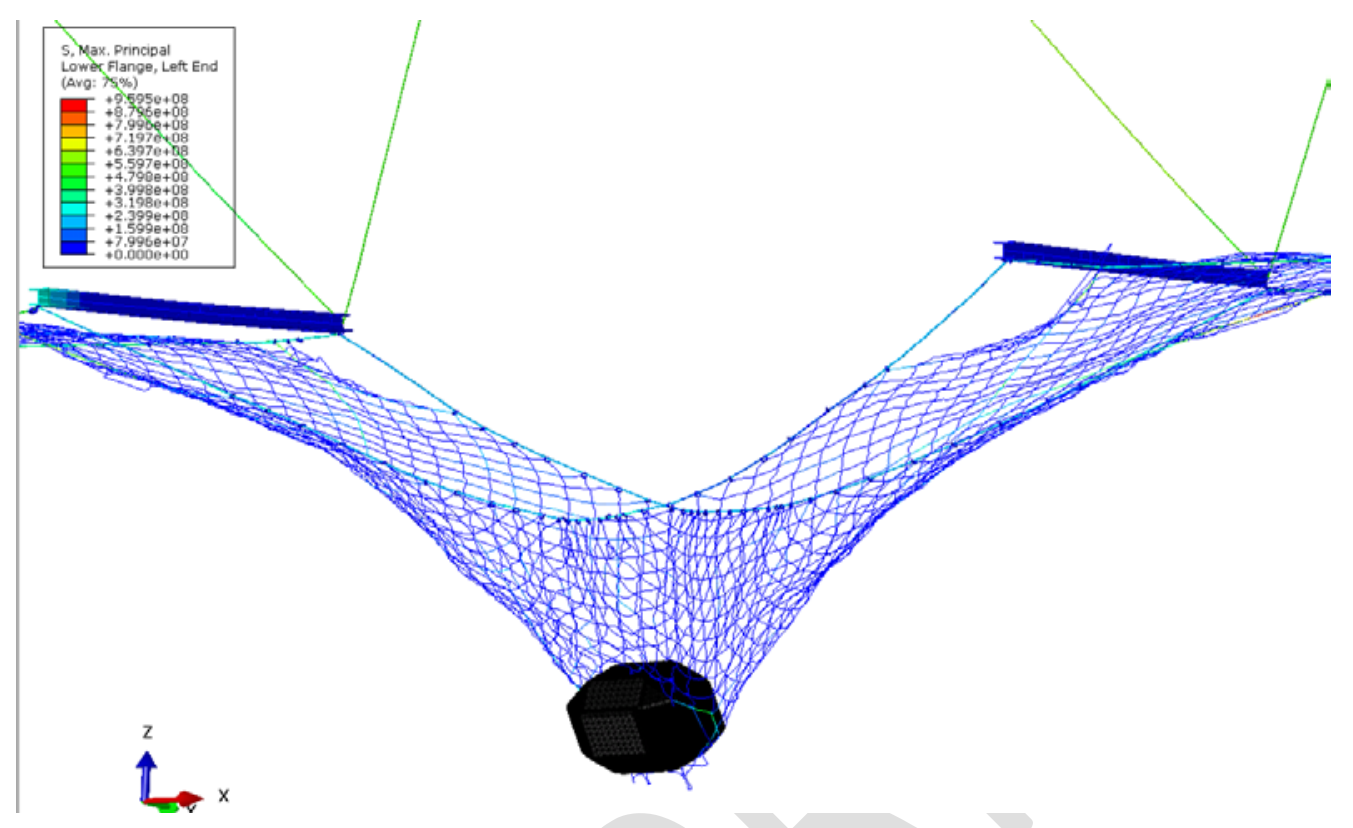

Figure 21. Failure mechanisms in S6 (the failure mechanism appear in models from S2 to S8)

The results of each model are shown in Figure 22, divided by their modifications with respect to the reference model. As expected, an increase of the height, the length, the net diameter and a reduction of the net grid of the barrier, besides an increment of the amount of material, also imply an increment of its maximal energy (Figure 23), following a linear trend. 

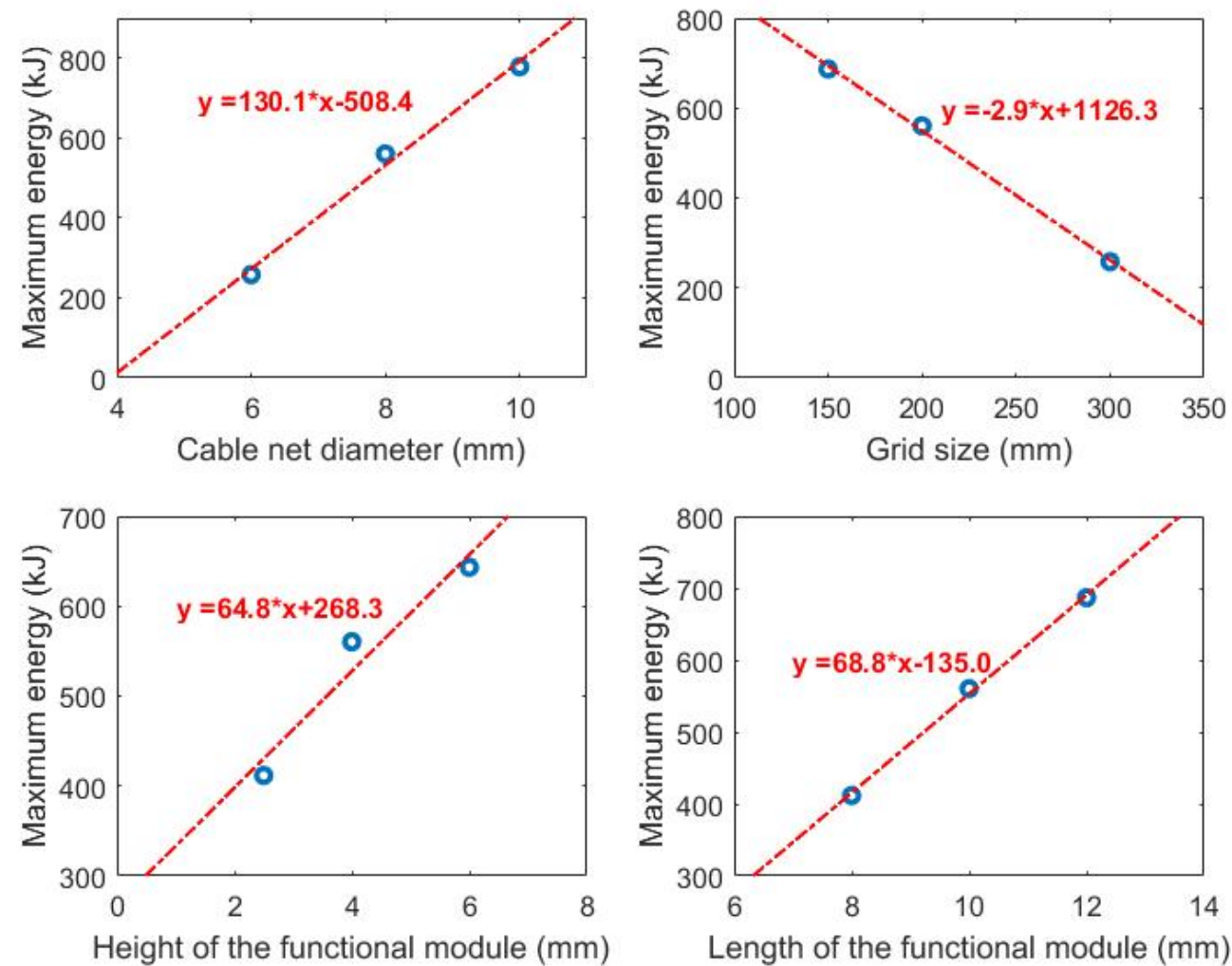

Figure 22. Maximum energy of the models classified by their geometrical modifications: a) net cable diameter, $b$ ) grid length of the net, $c$ ) high of the functional module and d) length of the functional module.

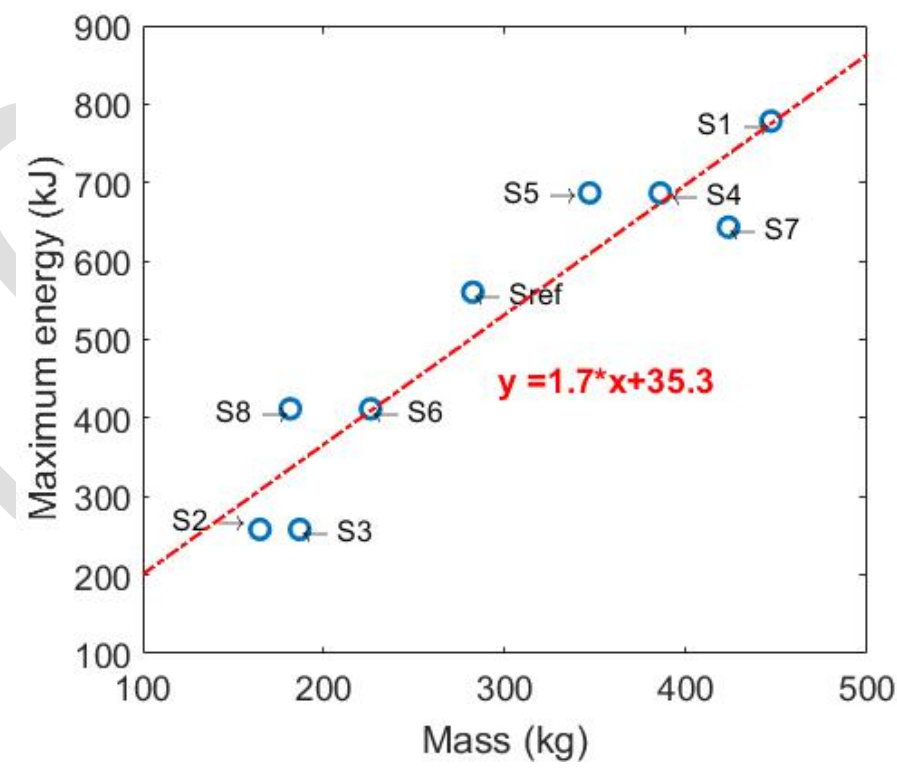

Figure 23. Maximum energy of the models in $\mathrm{kJ}$ versus net mass in $\mathrm{kg}$.

Models S1, S2, S3 and S4 have a variation on net density while S5, S6, S7 and S8 keep the density constant but change the barrier dimensions. Although, in general, an increase of the net mass 
result in an increase of energy (Figure 23), it has a steeper slope when a density variation occurs, as can be seen by the trend equations in Figure 24.
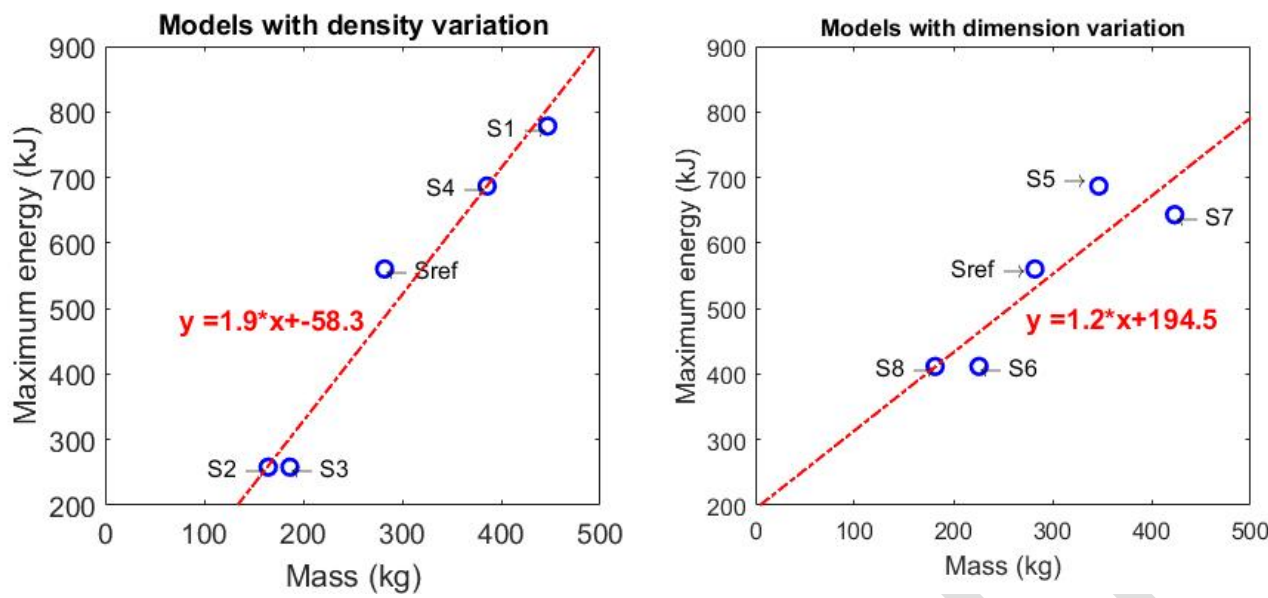

Figure 24. Energy trends in models a) with a net density variation, and b)with net dimensions variation.

From a manufacturer point of view, it is relevant to link the energy that one barrier is able to stop with some other parameter related with its cost. That is why an efficiency parameter is proposed in this work. Efficiency of each model is calculated as the maximal energy capacity divided by the net mass-, which is directly related to the cost-. It is not a parameter related with the effectiveness of a barrier to stop a block impact, but an indicator that helps the manufacturer to choose the best option in terms of saving of material among several possibilities that could be feasible for a specific energy aim

Using this efficiency parameter, simulation 8, a barrier of $10 \mathrm{~m}$ length, $2.5 \mathrm{~m}$ and $10 \mathrm{~mm}$ rope diameter, is the most efficient (Figure 25 a).

However, in absolute terms S8 does not improve the original barrier (Sref), since its maximum energy retention capacity is of only $411,7 \mathrm{~kJ}$ (Figure $25 \mathrm{~b}$ ), and its height of only $2.5 \mathrm{~m}$ could not be able to retain the falling rocks in case the rebounds exceed this measurement.

The selection of a barrier for its installation in a specific point of a slope is determined by the impact energy, the maximum separation of the rock from the slope and the length to protect. Useful tools to know these minimum requirements are rockfall simulation programs like "RockFall" or "CRSP" [12], in which rocks trajectory is predicted (including rebounds height, velocity an energy), after defining the slope geometry and material properties.

The best geometry of the interception structure that combines efficiency and maximum energy retention corresponds to $\mathrm{S} 5$, with a length of the functional modules of $12 \mathrm{~mm}$. 

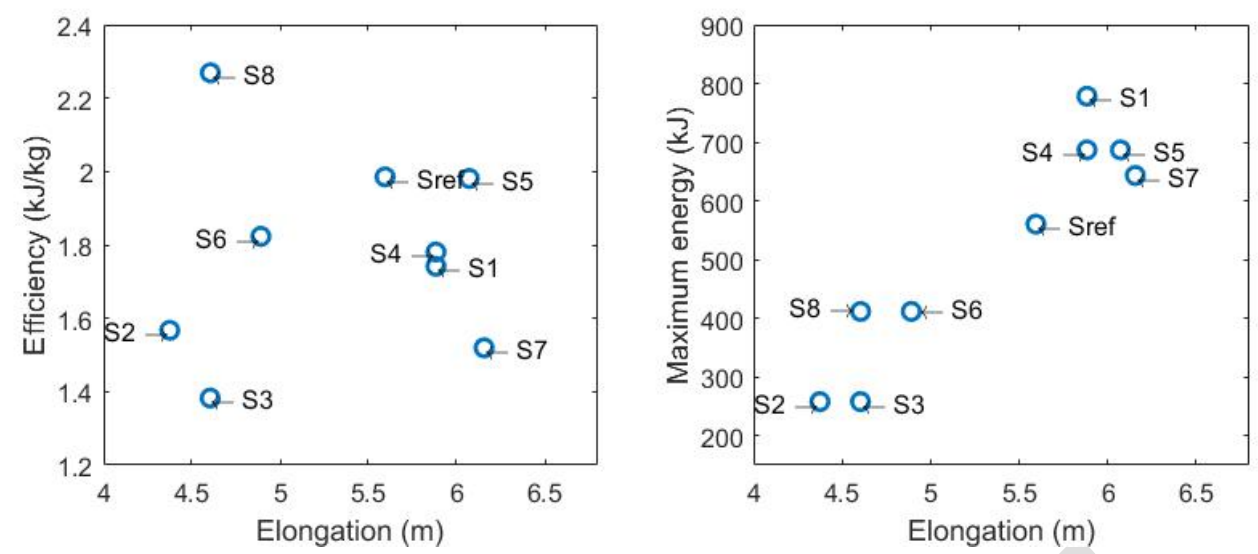

Figure 25. a) Efficiency versus maximum elongation of the barrier and b) Maximum energy versus maximum elongation of the barrier.

It has been detected that the sewing of the net and the perimeter cables could influence the maximum energy of the barrier. In these barriers the net is sewed very close to the posts ends. In this situation the curtain effect is limited in the adjacent modules, since, when the sewing square of the net reaches the post, the net is somehow blocked in those four points. When this happens, a cross shape stress distribution appears. Figure 26 illustrates this effect, where the most loaddemanded cables are plotted in red color. This net blocking also causes a stress concentration in the perimeter cables, especially at the shackles connected to the post.

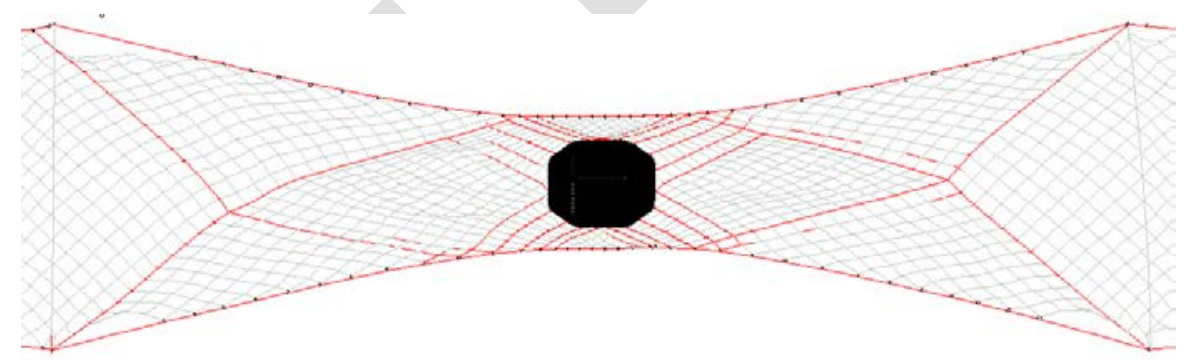

Figure 26. Cross-shape stress distribution (in red) in the central module.

\section{Conclusions}

In this paper two Finite Element models of rockfall barriers IBT-150 and IBT-500 have been developed and successfully validated with the results of experimental field tests. These models allowed a detailed study of this kind of structures in terms of their maximum energy retention.

Two modifications in IBT-150 were performed varying the number of brakes of the structure. The new calculations with the same impact energy of the block demonstrated that in both cases the barrier is still able to stop it, implying a valuable saving of money for both the manufacturer and the applicant of the barrier. In addition, the original configuration of barrier IBT-150 was founded to resist $294 \mathrm{~kJ}, 77 \%$ more than the experimentally tested.

Eight new models were developed in order to study the influence of geometrical factors related with the interception structure. The main conclusions for the survey are: 
- The higher energy capacity is reached increasing the diameter of the cable net from $8 \mathrm{~mm}$ to $10 \mathrm{~mm}$. The increase of dissipated energy is of $39 \%$.

- The most efficient model of barrier analyzed (S8) is not able to stop a block with as much energy as the reference model (tested with the ETAG recommendation).

- Manufacturers often offer their barriers within a range of length and high in which the geometry of the ETAG tested barrier is localized in the middle. Looking at the results, both a reduction of $2 \mathrm{~m}$ in the length of the modules and of 1,5 $\mathrm{m}$ in its high, the reduction of their capacity is of $26 \%$, so the minimum dimension able to retain the block with the energy specified is that certified by the ETAG.

- The best model that combines efficiency and absolute energy is also reached with an increase of the length of the barrier from 10 to $12 \mathrm{~m}$, followed by the model with a reduction of the grid size with respect to the reference model (Sref) to $150 \times 150 \mathrm{~mm}$. New experimental tests following the ETAG with these new designs will allow the manufacturer extend his range of products, adding higher energy capacity systems than the existent in his catalogue.

- The election of the geometry of the barrier for a landslide is function of the energy of the rocks, its maximal high and the length of the detachments. In case of more than one barrier that meets those targets, maximization of efficiency or minimization of mass will be chased. As an example, if $650 \mathrm{~kJ}$ energy impacts are predicted and it is necessary to cover a height of $4 \mathrm{~m}$ and a length of $30 \mathrm{~m}, \mathrm{~S} 1, \mathrm{~S} 4$ and S5 result to be adequate, but S5 is preferred as it is less over dimensioned, and uses less material, hence, less costs. However, if $450 \mathrm{~kJ}$ energy impacts are predicted and there will be not rebounds over 2.5 $\mathrm{m}, \mathrm{S} 6$ and S8 can cover the aims similarly, although S8 would be selected because of its highest efficiency.

Having corroborated that the models shown presented a reliable and good response according to the validation presented in section 3, some topics need to be improved to allow a deeper parametrical analysis in a future work. In this sense, maximum energy was assessed with a unique impact of the barrier, similar to a MEL impact. However, the ETAG also indicates that the barrier must resist two successive launches (with one third of the energy of the MEL). This was not included in this work, since some contact detection problems appeared after the first launch. Also, the computational cost of performing these two successive impacts would be much higher, as it is needed for the barrier to reach a resting state before the second impact. These issues are part of a currently ongoing research and will be further developed for future scientific contributions.

The non-sewing length of the net to the perimeter cables next to the post ends is a parameter that needs to be assessed and will have a great influence in the maximum energy capacity according to the observations in all the models. The expected result is that, as this length is higher, it also will be the energy retention. However, an upper limit will have to be stablished, since ETAG027 delimit the maximum height of the mesh at the post after the first SEL impact, which should be larger than the residual height.

\section{Acknowledgements}

The authors would like to thank MallaTalud Cantabria for the data provided and the permission to present it in this paper.

\section{References}


[1] Castanon-Jano L, Blanco-Fernandez E, Castro-Fresno D, Ballester-Muñoz F. Energy Dissipating Devices in Falling Rock Protection Barriers. Rock Mechanics and Rock Engineering, 2017; 50 (3), pp. 603-619. DOI: 10.1007/s00603-016-1130-x

[2] Gottardi G, Govoni L. Full-scale modelling of falling rock protection barriers (2010) Rock Mechanics and Rock

Engineering, 43 (3), pp. 261-274. DOI: 10.1007/s00603-009-0046-0.

[3] Bertrand D, Trad A, Liman A, Silvani C. Full-scale dynamic analysis of an innovative rockfall fence under impact using the discrete element method: From the local scale to the structure scale. Rock Mechanics and Rock Engineering, 45 (5),2012, pp. 885-900. DOI: 10.1007/s00603-0120222-5)

[4] Modelling of falling rock protection barriers, Govoni, L., de Miranda, S., Gentilini, C., Gottardi, G., Ubertini, F., 2011, International Journal of Physical Modelling in Geotechnics.

[5] Gentilini C, Govoni L, de Miranda S, Gottardi G, Ubertini F. Three-dimensional numerical modelling of falling rock protection barriers. Computers and Geotechnics, 2012; 44, pp. 58-72. DOI: 10.1016/j.compgeo.2012.03.011

[6] Escallón JP, Wendeler C, Chatzi E, Bartelt P. Parameter identification of rockfall protection barrier components through an inverse formulation. Engineering Structures, 2014; 77, pp. 1-16. DOI: 10.1016/j.engstruct.2014.07.019

[7] Escallón JP, Boetticher V, Wendeler C, Chatzi E, Bartelt P. Mechanics of chain-link wire nets with loose connections. Engineering Structures, 2015; 101, pp. 68-87. DOI: 10.1016/j.engstruct.2015.07.005

[8] Cazzani A, Mongiovì L, Frenez T. Dynamic finite element analysis of interceptive devices for falling rocks. International Journal of Rock Mechanics and Mining Sciences, 2002; 39 (3), pp. 303-321. DOI: 10.1016/S1365-1609(02)00037-0

[9] Mentani A, Giacomini A, Buzzi O, Govoni L, Gottardi G, Fityus S. Numerical modelling of a low-energy rockfall barrier: New insight into the bullet effect. Rock Mechanics and Rock Engineering, 2016, 49 (4), pp. 1247-1262. DOI: 10.1007/s00603-015-0803-1

[10] Koo RCH, Kwan JSH, Lam C, Ng CWW, Yiu J, Choi CE, Ng AKL, Ho KKS, Pun WK. Dynamic response of flexible rockfall barriers under different loading geometries. Landslides, 2016; pp. 1-12. DOI: 10.1007/s10346-016-0772-9

[11] Flexible rockfall barriers subjected to extreme loads, Volkwein, A., Roth, A., Gerber, W., Vogel, A., 2009, Structural Engineering International: Journal of the International Association for Bridge and Structural Engineering.

[12] Moon T, Oh J, Mun B. Practical design of rockfall catchfence at urban area from a numerical analysis approach. Geology, 2014; 172, pp. 41-56. DOI: 10.1016/j.enggeo.2014.01.004

[13] Mentani A, Govoni L, Gottardi G, Lambert S, Bourrier F, Toe D. A New Approach to Evaluate the Effectiveness of Rockfall Barriers. Procedia Engineering, 2016; 158, pp. 398-403. DOI: $10.1016 /$ j.proeng.2016.08.462

[14] Tran PV, Maegawa K, Fukada S. Experiments and dynamic finite element analysis of a wirerope rockfall protective fence. Rock Mechanics and Rock Engineering, 2013; 46 (5), pp. 11831198. DOI: $10.1007 / \mathrm{s} 00603-012-0340-0$ 
[15] Tran PV, Maegawa K, Fukada S. Prototype of a wire-rope rockfall protective fence developed with three-dimensional numerical modeling. Computers and Geotechnics, 2013; 54, pp. 84-93. DOI: 10.1016/j.compgeo.2013.06.008

[16] Escallón JP, Bartelt PA, Chatzi EN. Optimal design for high resistant rockfall barriers. Proceedings of the 5th International Conference on Computational Methods in Structural Dynamics and Earthquake Engineering (COMPDYN 2015): Volume 1, 2015 Hersonissos: National Technical University of Athens

[17] EOTA. Guideline for European technical approval of falling rock protection kits (ETAG 027), Febbraio 2008, Brussels.

[18] Coulibaly JB, Chanut MA, Lambert S, Nicot F. Sliding cable modeling: An attempt at a unified formulation, International Journal of Solids and Structures, Volumes 130-131, 2018, pp. 1-10, ISSN 0020-7683, DOI: 10.1016/j.ijsolstr.2017.10.025.

[19] ASTM E21-09, Standard Test Methods for Elevated Temperature Tension Tests of Metallic Materials, ASTM International, West Conshohocken, PA, 2009, www.astm.org

[20] Castro-Fresno D, Del Coz Díaz JJ, Garcia Nieto PJ, Norambuena Contreras J. Comparative analysis of mechanical tensile tests and the explicit simulation of a brake energy dissipater by FEM. International Journal of Nonlinear Sciences and Numerical Simulation, 2009; 10 (8), pp. 1059-1085

[21] de Miranda S, Gentilini C, Gottardi G, Govoni L, Mentani A, Ubertini F. Virtual testing of existing semi-rigid rockfall protection barriers. Engineering Structures, 2015; 85, pp. 83-94. DOI: 10.1016/j.engstruct.2014.12.022

[21] Volkwein A, Kummer P, Bitnel H, Campana L. Load measurement on foundations of rockfall protection systems (2016) Sensors (Switzerland), 16 (2), art. no. 174,. DOI: 10.3390/s16020174

[22] Castro-Fresno D, López Q L, Blanco-Fernandez E, Zamora-Barraza D. Design and evaluation of two laboratory tests for the nets of a flexible anchored slope stabilization system. Geotechnical Testing Journal, 2009; 32 (4), pp. 315-324. 